\title{
The Influence of Time Spent in Outdoor Play on Daily and Aerobic Step Count in
} Costa Rican Children

\author{
by \\ Maria del Rocio Morera Castro \\ A dissertation submitted to the Graduate Faculty of \\ Auburn University \\ in partial fulfillment of the \\ requirements for the Degree of \\ Doctor of Philosophy \\ Auburn, Alabama \\ August 6, 2011
}

Keywords: Outdoor play, Physical Activity, Obesity

Copyright 2011 by Maria Morera

Approved by

Mary E. Rudisill, Chair, Wayne T. Smith Distinguished Professor of Kinesiology

David M. Shannon, Humana-Germany-Sherman Distinguished Professor of

Educational Foundations, Leadership, and Technology

Danielle D. Wadsworth, Assistant Professor of Kinesiology

Leah E. Robinson, Assistant Professor of Kinesiology 


\begin{abstract}
There is strong evidence that children's health associated with obesity is a major concern for nations around the world (Sharma, 2007; Wang \& Lobstein, 2006). World efforts are being made to improve and protect their health. Research has shown that there are a number of variables associated with this obesity epidemic (i.e., poor nutritional habits, genetics, low socioeconomic status) (Koplan, Liverman, \& Kraak, 2005; U.S. Department of Health and Human Services, 1996), and that physical inactivity is a strong contributor (Cleland et al., 2008; Hands \& Parker, 2008). According to Sallis, Prochaska, and Taylor (2000) time spent outdoors is one of the most consistent predictors of children's physical activity. Evidence has also demonstrated that outdoor play has a positive impact in children's health (Clements, 2004; Frost, 2006; Pretty et al., 2007; Tabbush \& O'Brien, 2003; Taylor \& Kuo, 2008). However, the influence of time spent in outdoor play, and daily aerobic step count is less understood.

The purpose of this study is to examine the influence of time spent in outdoor play (i.e., on weekday and weekend days) on daily (i.e., average step count) and aerobic step count (i.e., average moderate to vigorous physical activity [MVPA] during the weekdays and weekend days) in fifth grade Costa Rican children. It was hypothesized that: (a) children who spent more time in outdoor play (as measured by item \#6 in the Children's Outdoor Play Survey) would demonstrate a higher daily step count for the weekdays (Monday through Friday), (b) children who spent more time in outdoor (as
\end{abstract}


measured by item \#7 in the Children's Outdoor Play Survey) would demonstrate a higher step count for the weekend days, (c) children who spent more time in outdoor play (as measured by item \#6 in the Children's Outdoor Play Survey) would demonstrate a higher daily aerobic (MVPA) step count for the weekdays, (d) children who spent more time in outdoor play (as measured by item \#7 in the Children's Outdoor Play Survey) would demonstrate a higher daily aerobic (MVPA) step count for the weekend days and (e) boys would demonstrate a higher daily and aerobic (MVPA) step count during weekdays and weekend days when compared to girls.

A total of 190 fifth grade children, from 3 public schools, participated in this study. After having attained parental letters of consent and children's assent forms (with appropriate signatures), the researcher measured the weight, height and stride length of all participants. An Omron HJ-720 ITC pedometer was distributed to each child and asked to wear it for one week (five week days and two weekend days) during waking hours to assess physical activity. At the end of the week the researcher collected the pedometers from the participants and administered the Children's Outdoor Play Survey.

Four 2 (Sex) x 3 (Time Spent Outdoors Groups) ANOVAs were conducted to determine the effects of Time spent outdoors on physical activity (pedometer step counts and aerobic step counts) for week days and weekend days. Results revealed a significant main effect for Groups (time playing outdoors), $F(2,184)=4.106, \eta 2=.043, p=.018$, and for Sex, $F(1,184)=8.600, \eta 2=.045, p=.004$, on daily average step count for the weekdays. Post hoc analyses indicated that the daily average step count was significantly lower for Group 1 (i.e., less than 1 hour) than for Group 3 (i.e., 3 hours or more), $F$ $(2,184)=4.106, p=.018$. Observing the means revealed that girls acquired significantly 
fewer step counts than boys for the weekdays. There was no interaction between Groups and Sex on daily step count for weekdays.

The analyses also indicated a main effect for Sex on daily average step count for weekend days $F(1,184)=4.873, \eta 2=.026, p=.029$. Similarly to the weekdays, the girl's daily average step count for the weekend days was significantly lower than the boys. There was no Group main effect of time spent playing outdoors and no interaction between Groups and Sex on daily step count for weekend days.

Results also showed that there was a main effect for sex on daily aerobic step count for weekdays, $F(1,184)=11.105, \eta 2=.057, p=.001$ and on daily aerobic step count for weekend days, $F(1,184)=6.012, \eta 2=0.32, p=.015$. Girls average fewer aerobic step counts than boys. There was no Group main effect and no interaction between Groups and Sex on daily aerobic step count for the weekday and weekend days.

In conclusion, it appears that encouraging children to spend three or more hours in outdoor play may be a useful strategy for increasing daily step counts over the weekdays. Results also reveal that boys engaged in more daily steps and more daily aerobic steps than girls in daily step counts for all days of the week; and that few children who participated in this study sample actually met the United States daily step count recommendation. Finally, the findings revealed that daily average step counts and average aerobic step counts for the weekend days are lower for Costa Rican fifth grade children when compared to the weekdays. These findings have implications for the health of Costa Rican children. Future policy recommendations in Costa Rica should focus on promoting children's physical activity engagement and outdoor play. 


\section{Acknowledgments}

To all the people in Auburn that day by day with a smile, a hello, a chatting, a shaking hand, a hand to help, or a hug provides me with the strength to finish my degree. Thank you Robin, Nan, Tiffany, Dr. Hastie, John, Paul, Sam, Colleen, Dr. Waimer, and many others.

Special thank you to Dr. Rudisill for brings me the opportunity to make a dream come true. Many thank you for all your support and help through all this process. Uncle Roy you are an amazing person. To my Committee Members, External Reader, Faculty Members, thanks you so much for your guidance, patience and teachings.

Gracias Costa Rica. Don Leonardo gracias por brindarme los permisos y toda la colaboración para que la investigación fuera todo un éxito. Muchísimas gracias, a los y la directora de los centros educativos, los y las maestras (as), padres, madres de familia. Un agradecimiento muy especial a los y las estudiantes que con todo su entusiasmo y responsabilidad participaron en este estudio. A la Universidad Nacional y toda su gente por la ayuda y colaboración en todo este proceso, infinitas gracias.

A mi familia de sangre y mis familias del alma, las palabras en este momento me sobran y quizás solo puedo resumirlo en dos palabras les amo.

"Nunca he visto un animal salvaje compadecerse de si mismo. Un pájaro morirá de frio en una rama y jamás se habrá compadecido de si mismo..." 


\section{Table of Contents}

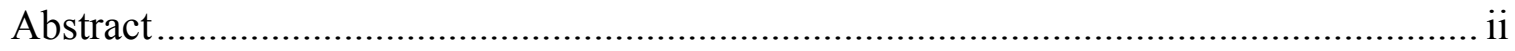

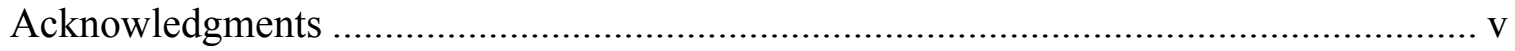

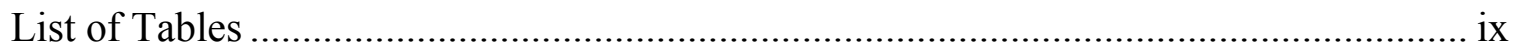

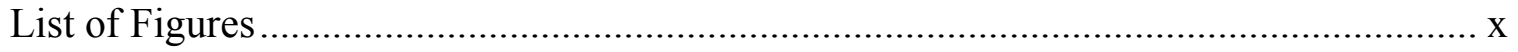

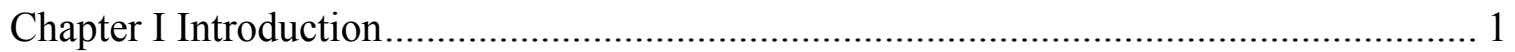

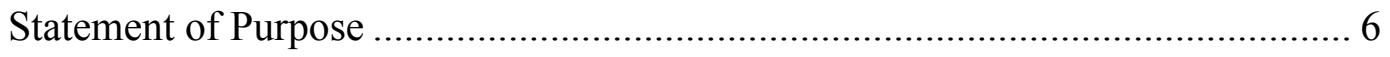

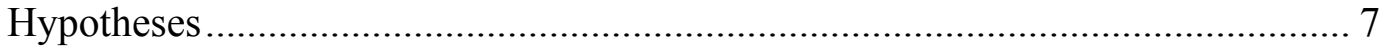

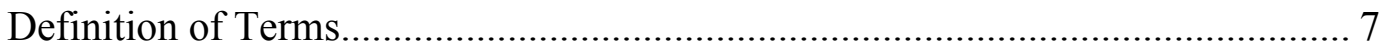

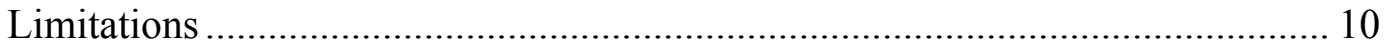

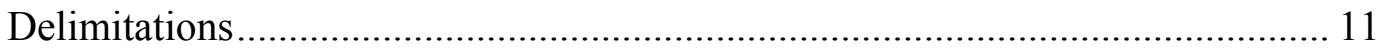

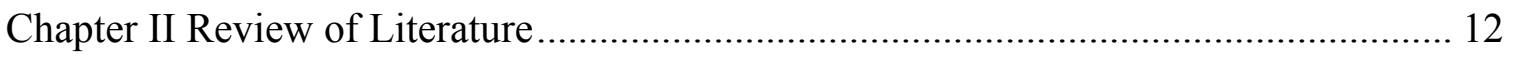

Physical Activity and Public Health ............................................................. 12

Physical activity and children's health. .............................................. 13

Physical activity status in children.................................................... 15

Physical activity recommendations for children.................................. 18

Physical activity dimensions............................................... 20

Children's physical activity determinants.................................. 22 
Outdoor Play and Public Health. ............................................................. 25

Outdoor play and children's health................................................. 27

Children and the amount of time they spend outdoors. ....................... 29

Outdoor time, intensity and physical activity.................................. 31

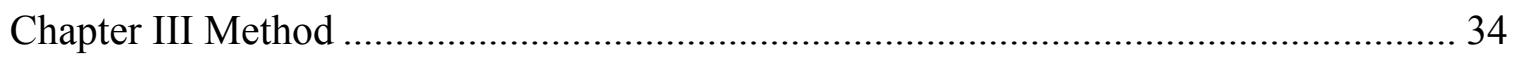

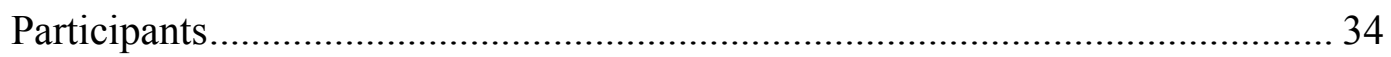

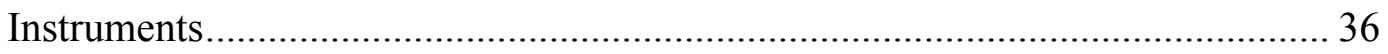

Outdoors play- Children's Outdoor Play Survey................................. 36

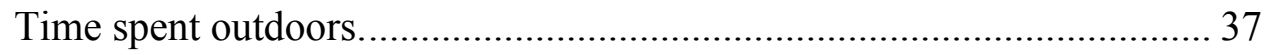

Demographic information.......................................................... 38

Physical activity - Pedometers......................................................... 38

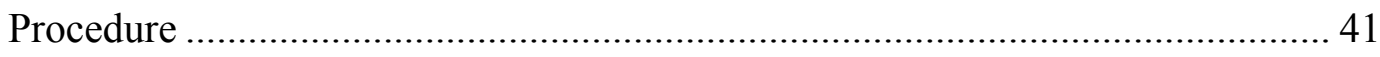

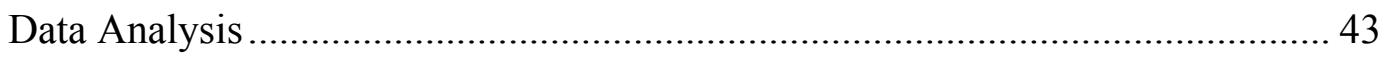

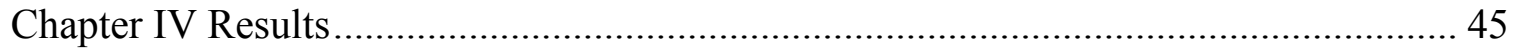

Daily Pedometer Step Count for Weekdays and Weekend Days ...................... 47

Average Step count for Weekdays................................................... 47

Average Step count for Weekends Days. ......................................... 48

Aerobic Pedometer Step Count for Weekdays and Weekend Days ................... 49

Average Aerobic Step Count for Weekdays...................................... 49

Average Aerobic Step Count for Weekends Days............................... 50

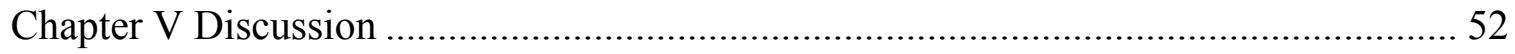

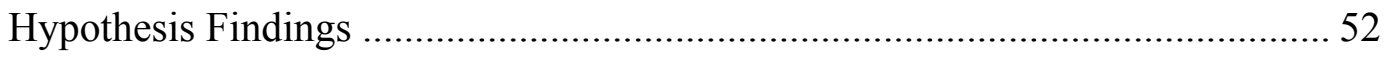


Average Step count for Weekdays................................................ 52

Average Step count for Weekend Days. ........................................... 54

Aerobic Pedometer Step Count for Weekdays and Weekend Days. ........ 58

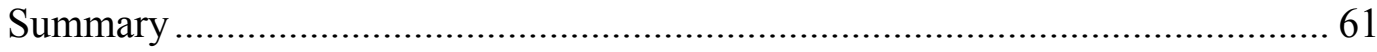

Conclusions and Future Research Recommendations ................................... 61

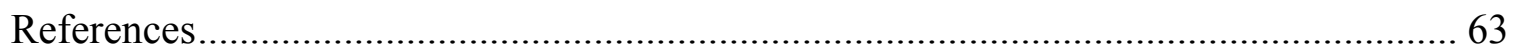

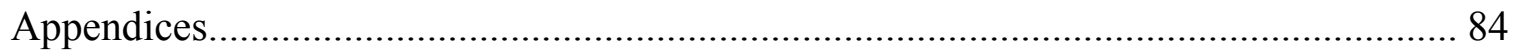

Appendix A-Descriptive Information Pertaining to each Participating School............ 85

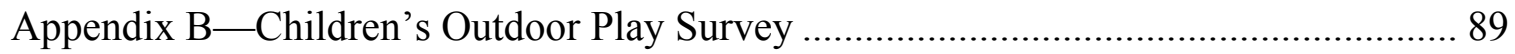

Appendix C_Letter to Parent/Guardian's Consent .................................................. 98

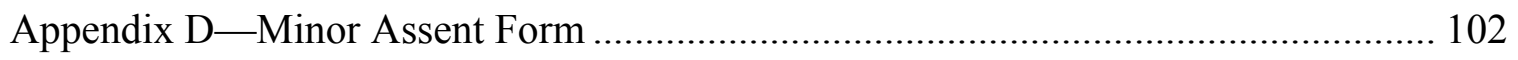

Appendix E-Outdoor Activities Reported by Children Who Met the Step Count

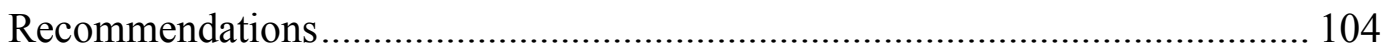


List of Tables

Table 1 Summary of Obesity and Overweight Rates for Various Countries

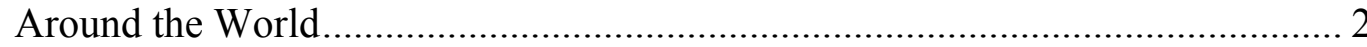

Table 2 Participant's Demographic Information ................................................... 36

Table 3 Reported Percentages of Time in Outdoor Play from Pilot Test Sample and the Study Sample by Group ...................................................... 38

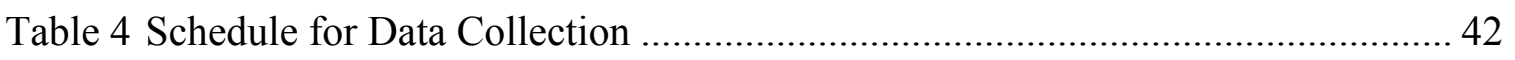

Table 5 Participant Height and Weight Means and Standard Deviations by

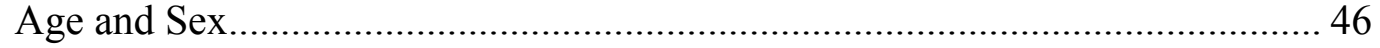

Table 6 Weekdays and Weekend Days Average Step Count and Aerobic

Step Count Means and Standard Deviations for Time Spent

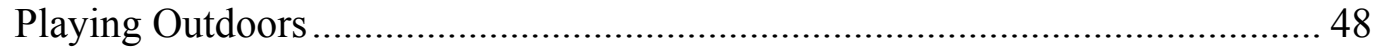

Table 7 Weekdays and Weekend Days Average Step Count and Aerobic

Step Count Means and Standard Deviations for Males and

Females

Table 8 F values on Time Spent Playing Outdoors Group and Sex Main

Effects and Interactions for the dependent variables.................................... 51

Table 9 Top Five Outdoor Activities that Children Engaged during Data

Collection Week

Table 10 Descriptive Information Pertaining to Each Participating School.................... 86

Table 11 Environmental context Pertaining to Each Participating School...................... 88

Table 12 Top Weekday Outdoor Activities Reported by the Boys and Girls Who Met the Step Count Recommendations

Table 13 Top Weekend Day Outdoor Activities Reported by the Boys and Girls Who Met the Step Count Recommendations 106 
List of Figures

Figure 1. Photograph of participants wearing the pedometer........................................ 40 


\section{Chapter I}

Introduction

In the last three decades, a public health crisis associated with obesity has been the focus of attention for many nations around the world. Globally, obesity has reached epidemic proportions with over a billion people classified as overweight and of those at least 30\% were obese (Wang, Monteiro, \& Popkin, 2002). An estimated 22 million children under 5 years of age are overweight (Malecka-Tendera \& Mazur, 2006) and 10\% of school-age children have been classified as overweight (Lobstein, Baur, \& Uauy, 2004). Childhood obesity rates are dramatically changing at an alarming rate in many countries (International Association for the Study of Obesity [IASO], 2010; Sharma, 2007). Refer to Table 1 for a summary of obesity and overweight rates for various countries around the world.

Latin American and the Caribbean countries are among those reporting increases in obesity. In children 1 to 5 years of age, the prevalence of overweight ranged from $6 \%$ in Haiti, 24\% in Peru, and 24\% of Mexican-American children (Martorell, Khan, Hughes, \& Grummer-Strawn, 1998). During 2002 in Chile, 29\% of 6-year-old boys and 27\% of girls were obese. In 2006, the prevalence of overweight among 5 to 17 year old children from Mexico was $30 \%$ in boys and $31 \%$ in girls (IASO, 2010). Costa Rica is not an exception to this epidemic. The overall prevalence of overweight and obesity in school children from urban and rural areas of Costa Rica ( 7 to 12 years of age) were $34.5 \%$ and 
26.2\%, respectively (Núñez-Rivas, Monge-Rojas, León, \& Roselló, 2003).

Table 1

Summary of Obesity and Overweight Rates for Various Countries Around the World

Range of Overweight \%

Country Children's Age Period (including obesity)

\begin{tabular}{|c|c|c|c|c|}
\hline & & & Boys & Girls \\
\hline Japan & 6 to 14 years & $1996-2000$ & $16 \%$ & $14 \%$ \\
\hline England & 5 to 17 years & 2007 & $23 \%$ & $27 \%$ \\
\hline Spain & 7 to 11 years & 1998 to 2000 & $38 \%$ & $30 \%$ \\
\hline Australia & 9 to 13 years & 2007 & $25 \%$ & $30 \%$ \\
\hline Germany & 5 to 17 years & 2003 to 2006 & $20 \%$ & $20 \%$ \\
\hline France & 11 to 17 years & 2006 & $21 \%$ & $17 \%$ \\
\hline Portugal & 7 to 9 years & 2002 to 2003 & $30 \%$ & $34 \%$ \\
\hline Netherlands & 5 to 16 years & 2003 & $15 \%$ & $18 \%$ \\
\hline Switzerland & 6 to 13 years & 2007 & $17 \%$ & $13 \%$ \\
\hline India & 5 to 15 years & 2002 & $13 \%$ & $8 \%$ \\
\hline Slovenia & 6 to 19 years & 2007 & $30 \%$ & $24 \%$ \\
\hline Brazil & 7 to 10 years & 2002 & $23 \%$ & $21 \%$ \\
\hline United States & 6 to 17 years & 2003 to 2004 & $35 \%$ & $36 \%$ \\
\hline Canada & 12 to 17 years & 2004 & $32 \%$ & $26 \%$ \\
\hline
\end{tabular}


With this growing increase in obesity, national efforts need to be made to improve and protect the health of its citizens. Efforts are being made to better understand the cause of this global obesity epidemic and to promote healthier lifestyles, particularly for children who are at-risk of becoming overweight and obese in childhood and maintaining that health status throughout adulthood. Researchers are finding that there are a number of variables associated with the obesity epidemic (i.e., poor nutritional habits, genetics, low socioeconomic status) (Koplan, Liverman, \& Kraak, 2005; U.S. Department of Health and Human Services, 1996), and that physical inactivity is a strong contributor (Cleland et al., 2008; Hands \& Parker, 2008).

Physical activity has been identified as an important factor in combating the crisis of obesity (Pangrazi, Beighle, Vehige, \& Vack, 2003) and plays a critical role in children's health, social interaction, wellbeing, and setting healthy lifestyle habits (Sallis, Prochaska, \& Taylor, 2000). Studies show that children, who are more sedentary during the early years, have a tendency towards inactivity later in life. Pate, Baranowski, Dowda, and Trost (1996) reported that 3- to 4-year-old children, who are less physically active than their peers, remain less active as they grow older. In addition, physical activity participation typically declines into adolescence and adulthood (Centers for Disease Control and Prevention [CDC], 1998; Pate, Long, \& Heath, 1994). According to Rowland (1990), physical activity declines with age, resulting in a 50 percent decrease among children and adolescents between ages 6 and 16. Oliver, Schofield, and Kolt (2007) reported that young children participate in very little vigorous physical activity 
and high levels of sedentary behaviors. It is apparent that physical inactivity is contributing to the obesity epidemic in children and adults.

Considerable attention is being directed toward physical activity and inactivity and what factors play an important role. A recent model, "the social-ecological approach", explains the unique interaction between one's attributes and health behavior as well as the social, government policy and physical environments that surrounds and influences the individual. This model suggests that there are multiple levels of environmental influence (e.g. individual, social, cultural, physical, institutional) that can directly and indirectly influence behaviors such as physical activity. Although individual and social factors were the primary focus of research in this area for a number of years (Bronfenbrenner, 2005; Sallis \& Owen, 2002), a recent trend for researchers is to investigate how environmental factors can influence children's physical activity behaviors.

The ecological model proposes that children's physical activity may be influenced by their access to safe places to play, their friendship groups, and local policy regarding outdoor spaces (Veitch, Bagley, Ball, \& Salmon, 2005). Studies suggest that access to natural environments is important for healthy child development, and influential in developing lifelong patterns of outdoor behavior into adulthood (Ward Thompson, Aspinall, \& Montarzino, 2008).

According to Dietz (2006) opportunities for spontaneous play may be the only requirement that young children need to increase their physical activity. Play has the potential to improve all aspects of children's wellbeing: physical, emotional, social, and cognitive (Burdette \& Whitaker, 2005). Play is essential for children's adaptation to their 
culture, society and world. Play promotes cognitive development, social development, language development, physical fitness and health (Frost, 2006). Frost (2006) also suggests that play is active, creative, and social, engages the body in fine, gross and manipulative motor development and the mind in negotiation, problem solving, imagination and flexibility. Through the interactions that children have with the environment when engaged in play, they gain control and ultimate mastery over their bodies (Little \& Wyver, 2008).

Researchers have investigated children's play and the role of outdoors in play experiences and physical activity behavior (Fjørtoft, 2001; Frost, 2006). Sallis, Prochaska, and Taylor (2000) concluded that time spent outdoors is one of the most consistent predictors of children's physical activity. Spending time outdoors has been also related to children's motor development. Children's development of strength, balance, endurance and coordination are positively influenced with involvement in outdoor play (Fjørtoft, 2001). Children who have the choice to freely select the type of outdoor play activities have the most successful experiences because they are selfmotivated, find the play more enjoyable, and are process-oriented. By engaging in freely chosen, authentic outdoor play activities children can also learn certain skills (e.g. social competence, problem solving, creative thinking, and safety skills) necessary for adult life, and increase their desire to be active (Clements, 2004). In addition, outdoor play improves children's physical, intellectual and social development (Little \& Wyver, 2009).

This relationship between outdoor play and physical activity is less understood. However one recent cross-sectional study conducted over three years with children ages 5 
to 6 and 10 to 12 concluded that encouraging these age groups to spend more time outdoors can be an effective strategy for increasing physical activity and preventing overweight and obesity (Cleland et al., 2008). Findings showed that 10 to 12 year old elementary school-aged children who spent more time outdoors, tended to be more active and presented a lower prevalence of overweight than those children who spend less time outdoors. These findings suggest that outdoor play can influence physical activity engagement. However, there is more research needed to better understand this relationship and the important factors that contribute to it. For example, understanding the role of physical activity intensity to outdoor play is important with respect to weight control and obesity. In order for children to meet the recommended physical activity guidelines, they must engage in at least 60 minutes and up to several hours of daily, of age-appropriate physical activity on all, or most days of the week. Most of the 60 or more

minutes a day should be engaged in either moderate or vigorous intensity. Cleland et al. (2008) also found that spending more time outdoors for older boys was predictive of higher levels of moderate to vigorous physical activity (MVPA). This finding inversely predicted the prevalence of overweight among older children three years later and strongly suggests that outdoor play is an important variable to consider with respect to physical activity and the global obesity epidemic.

\section{Statement of Purpose}

Unfortunately, the only published study with respect to Costa Rican children's weight status has demonstrated that obesity is increasing at an alarming rate. This situation and the lack of information about the current condition of Costa Rican children's physical activity, time spent playing outdoor, and intensity suggests a need to 
better understand their outdoor physical activity. The purpose of this study is to examine the influence of time spent in outdoor play (i.e., on weekdays and weekend days) on daily (i.e., average steps count) and aerobic step count (i.e., average moderate and vigorous physical activity [MVPA] during the weekdays and weekend days) in fifth grade Costa Rican children.

\section{Hypotheses}

In the current study, it was hypothesized that:

1. Children who spent more time in outdoor play (as measured by item \#6 in the Children's Outdoor Play Survey) would demonstrate a higher daily step count for weekdays (Monday through Friday).

2. Children who spent more time in outdoor play (as measured by item \#7 in the Children's Outdoor Play Survey) would demonstrate a higher daily step count for the weekend days.

3. Children who spent more time in outdoor play (as measured by the Children's Outdoor Play Survey) would demonstrate a higher daily aerobic (MVPA) step count for the weekdays (Monday through Friday).

4. Children who spent more time in outdoor play (as measured by the Children's Outdoor Play Survey) would demonstrate a higher daily aerobic (MVPA) step count for the weekend days.

5. Boys would demonstrate a higher daily step count and daily aerobic (MVPA) step count during weekdays and weekend days when compared to girls.

\section{Definition of Terms}

Aerobic physical activity. Activity in which the body's large muscles move in a 
rhythmic manner for a sustained period of time. Aerobic activity, also called endurance activity, improves cardiorespiratory fitness. Examples include walking, running, and swimming, and bicycling (Centers for Disease Control and Prevention [CDC], 2010). Aerobic step count is the average number of steps achieved at moderate to vigorous intensity level (3 METs or more) accumulated throughout the day. The aerobic step is recorded each time a person satisfies the following two conditions: walk more than 60 steps per minute and walk for more than 10 minutes continuously without taking a break over one minute (OMRON Healthcare, 2007).

Daily Step Counts (DSC) is the average number of steps accumulated throughout the day (Beighle \& Pangrazi, 2006).

Fifth grade Costa Rican students include children ages 10 to 13 years of age who are registered in a public school located in San Jose, Costa Rica.

Intensity refers to how much work is being performed or the magnitude of the effort required when performing an activity or exercise (CDC, 2010). For this study, the Omron HJ-720 ITC pedometer was used to measure intensity.

Inactive or sedentary refers to people who do only or beyond baseline activity are considered physically inactive. For example standing and sitting are classified as inactive (U. S. Department of Health \& Human Services [HHS], 2008).

Light-intensity activity is defined as activities beyond baseline such as standing, walking slowly, lifting lightweight objects (HHS, 2008). This is also equivalent to activities that are completed at less than 3 METs (Ainsworth et al., 2000).

Metabolic equivalent (MET) is a unit useful for describing the energy expenditure of a specific physical activity. For example, 1 MET is considered a resting metabolic rate 
obtained during quiet sitting (Ainsworth et al., 2000).

Moderate-intensity activity is defined as activity that results in increases in heart rate and respiration compared to normal (hearth beating faster than normal and they are breathing harder than normal). Some examples are: active recreation such as hiking, skateboarding, and bicycle riding (HHS, 2008). This is also equivalent to physical activity that is completed at 3-5.9 METs (Ainsworth et al., 2000).

Physical activity is any bodily movement produced by the contraction of skeletal muscle that increases energy expenditure above a basal level. In this study physical activity will refer to bodily movements that enhance health (HHS, 2008).

Outdoor activities include any experiences that take place in the outside the confines of a building (i.e., outside, open-air activities); and do not involve organized competition or activities that have formal rules.

Outdoors environments include public and private outside spaces. Most often outdoor environments incorporate some degree of interaction with nature, fresh air and sunshine. These environments can include urban green spaces such as domestic and communal gardens and urban parks or less managed spaces such as the open countryside, forests, and coastal and mountain areas (Pretty et al., 2007).

Outdoor play is freely chosen play that is personally directed [outdoors] (NPFA, Children's Play Council, \& PLAYLINK, 2000).

Time spent outdoors is defined as the length of time in minutes/hours spent in the outdoor on a daily basis.

Vigorous-intensity activity results in rapid heart rate and increases respiration when compared to a resting state (feels heart beating much faster than normal and breathe much 
harder than normal). Some examples are: active games involving running and chasing, jumping rope, martial arts, sports such as soccer, basketball, tennis (HHS, 2008). This is also equivalent to physical activity that is completed at 6 METs or more (Ainsworth et al., 2000).

\section{Limitations}

Limitations associated with this study included:

The conditions of interest were implemented in a naturalistic setting. Although care was taken to control for variables that may impact the results of the study (i.e., protocol for wearing the pedometers was consistent, the week that children wore the pedometers was the same week they referred to the survey, execution of a pilot test to verify understanding of the survey), it was impossible to control for all variables.

The outdoor conditions in Costa Rica are very different from other countries that have extreme ranges in temperature (i.e., temperatures above $32^{\circ} \mathrm{F}$ or over $100^{\circ} \mathrm{F}$ ). The average temperature throughout the year in Costa Rica is between $71^{\circ} \mathrm{F}$ and $81^{\circ} \mathrm{F}$. Costa Rica has a temperate tropical climate marked by two seasons: the dry (December to April) and the rainy (May to November). Therefore the findings may not be generalizable to other countries with extreme weather conditions and where children's outdoor activities may differ significantly.

The sample of children was recruited to be representative of the city (i.e., range of physical and social environments), however the findings may not be representative for other areas in Costa Rica such as rural areas.

Since time spent in outdoor playing was a self-report measure, it could be possible that children underestimated or overestimated their time spent in outdoor play, however 
the self-reported measure was consistent with the information reported by children used for the pilot test. According to Piaget $(1969,1970)$ children ages 7 to 9 are able to integrate the concepts of distance, time, and speed successfully. By ages 10 and 11, children have gained an understanding of time and the chronology of past events (Harms \& Lettow, 2007). However, some children will take longer to develop these concepts because they are related to intellectual growth (Inhelder and Piaget, 1962), interaction with the environment (Wadsworth, 1996), and sociocultural backgrounds (Zhou, Peverly, Boehm, \& Chongde, 2000). New technology has been developed that allows for the distinction between indoor and outdoor time. In future investigations, this new technology may be used to substitute the children's self-report measure as a more accurate measurement of time in outdoor and indoor settings.

\section{Delimitations}

The delimitations of this study were:

Fifth grade children from 3 schools in the Central Valley of Costa Rica were assessed. Therefore the findings may not be generalized to all fifth grade children around the world or from other regions of Costa Rica. 


\section{Chapter II}

\section{Review of Literature}

The purpose of this study is to examine the influences of time spent in outdoor play (i.e., on weekdays and weekend days) on daily (i.e., average steps count) and aerobic step count (i.e., average moderate and vigorous physical activity [MVPA] during the weekdays and weekend days) in fifth grade Costa Rican children. The following section will provide a review of the literature associated with physical activity and outdoor play as important components to public health. Specifically this section will present and summarize the research literature pertaining to (a) physical activity and children's health that includes physical activity status in children and physical activity recommendations for children. (b) Outdoor play and children's health including outdoor activity and children's benefits as well as the amount of time children spent outdoors, and (c) outdoor time and physical activity.

\section{Physical Activity and Public Health}

Physical activity is a well documented and recognized variable associated with healthy lifestyle, and is defined as body movement produced by skeletal muscles that result in energy expenditure (Caspersen, Powell, \& Christenson, 1985). The World Health Organization (WHO) has discussed the links between physical activity and good health. WHO (2010) experts propose that physical activity is a key determinant of energy expenditure and may benefit health through positive effects on balance; hypertension; 
osteoarthritis; body weight and composition; control over risky behaviors (e.g.

tobacco/alcohol/substance use, violence and unhealthy diet); and mental and psychological health by reducing depression, anxiety, and stress. There are also social benefits associated with physical activity such as improved performance, increased productivity and lower worker absenteeism.

There is strong evidence that an individual who is physically active benefits from a lower risk of coronary heart disease (i.e., stroke, $\mathrm{CHD}$, coronary artery disease, and hypertension), type 2 diabetes, and reduces the risk of certain types of cancers such as colon, breast cancer (Department of Health, Physical Activity, Health Improvement and Prevention, 2004), lung, endometrial and advanced prostate cancer (Miles, 2007).

Regular physical activity is an effective preventive strategy for the maintenance of bone mineral density and the fight against osteoporosis (Warburton, Nicol, \& Bredin, 2006). Physical activity has been associated with other important heath outcomes such as preventing injuries and falls. Furthermore people who are active are more effectively adapt to use fat as an energy substrate. Body composition is also positively influenced by physical activity, by decreasing fat mass even if bodyweight remains unchanged. Regular physical activity is also associated with beneficial changes to the immune system, beneficial effects on the body's capacity for breaking down and forming blood clots, and lowers the risk of upper respiratory tract infections (Miles, 2007).

\section{Physical activity and children's health.}

Physical activity is an important part of a child's daily routine and healthy lifestyle. Extensive research has shown that regular physical activity provides important health benefits for children and youth. Physical activity has been shown to be important 
for children's social, mental and physical health, and has been identified as a critical component for health across the lifespan (Boreham \& Riddoch, 2001). Research suggests that an active lifestyle during childhood reduces the risk of health problems in later years (Sallis et al., 2000). Physical activity is positively related to good health, happiness and vitality in young children (Miles, 2007). It is one of the most important medium through which children form impressions about themselves as well as about their surroundings (van Sluijs, McMinn, \& Griffin, 2007). Physical activity helps children develop social skills, improve mental health and reduce risk-taking behaviors (Taras, 2005). It is also important for wellbeing, mood, and setting good lifestyle habits (Miles, 2007).

Specific health benefits associated with physical activity engagement in children are well documented. These include: maintaining energy, balance, muscle strength, and flexibility. A large volume of activity incorporating a wide variety of movements and many muscle groups, promotes children's cardio-respiratory development, muscular endurance, speed, power, and flexibility (Boreham \& Riddoch, 2001). In childhood, physical activity habits have a long-lasting effects on bone health. High impact activities (e.g., running, gymnastics, and jumping) are an effective way to increase bone strength (Miles, 2007). High levels of physical activity have been associated with improvement on self-esteem in children and adolescents (Strauss, Rodzilsky, Burack, \& Colin, 2001).

Increases in physical activity are considered to be beneficial in attending to children's health such as obesity (Dietz, 2006), bone density, blood pressure, (Boreham \& Riddoch, 2001), musculoskeletal health, cardiovascular health, physical self-concept, anxiety, depression symptoms, academic performance, and classroom children's behavior (Strong et al., 2005). Also physical activity has been associated with improved 
psychological wellbeing, gaining more self-confidence and higher self-esteem, raising HDL ("good") cholesterol, and reducing the risk of diabetes and some kinds of cancer later in life (American Heart Association, 2010). Physical activity has been associated with beneficial changes in triglycerides, insulin resistance and adiposity in children (Brage et al., 2004). In addition, children with asthma who are physically active experience decreased severity of asthma symptoms (Lang, Butz, Duggan, \& Serwint, 2007). However, despite all the benefits associated with physical activity engagement, children are not accumulating enough physical activity to reap these health benefits.

\section{Physical activity status in children.}

Children are more active than adults, but research has indicated that a large number of children from around the world do not engage in sufficient activity during childhood to gain health benefits. For example, a 2008 British Health Survey found that approximately $32 \%$ of boys and $24 \%$ of girl's ages $2-15$ years achieved the government's recommendation for physical activity (e.g. at least 60 minutes of moderate intensity physical activity each day). Overall, $95 \%$ of boys and girls had participated in some kind of physical activity in the last seven days. The responses indicated that the children averaged 10.0 hours for boys and 8.7 hours of physical activity for girls in the week prior to completing the survey. Levels of physical activity among girls declined with age, from a mean of $35 \%$ among 2 year olds to $12 \%$ among 14 year olds. On average, boys and girls acquired similar amounts of light activity. Overall, boys spent 85 minutes per day and girls spent 61 minutes per day on average in moderate to vigorous physical activity (MVPA). MVPA decreased from 124 minutes among boys and 101 minutes among girls ages 4 to 7, to 52 minutes among boys and 28 minutes among girls ages 12 to 15 (Craig, 
Mindell, \& Hirani, 2009).

According to the United States National Survey of Children's Health in 2007, the percentage of children ages 6 to 17 years who engaged in vigorous physical activity during a full week was: (a) 10.3\% engaged in 0 days of physical activity, (b) $25.4 \%$ engaged in 1 to 3 days, (c) $34.4 \%$ engaged in 4 to 6 days, and (d) $29.9 \%$ engaged in daily physical activity (U.S. Department of Health and Human Services, 2009). According to Strauss, Rodzilsky, Burack, and Colin (2001) children spent only 12 to 13 minutes per day involved in vigorous physical activity. Hinkley, Crawford, Salmon, Okely, and Hesket (2008), and Miles (2007) reported that boys in the United States tend to be more active than girls, and there is a decline in physical activity as children reach adolescence, a tendency that is more prevalent in girls.

In New Zealand, two-thirds (67.1\%) of children and youth people achieved the physical activity guidelines, but this proportion decreased with age. An average of $81 \%$ of children between 10 to 14 years of age met the guidelines. On average, children and young people participated in 105 minutes per day of moderate to vigorous intensity physical activity (MVPA). In all age groups boys were significantly more active than girls. In addition, more time was spent in MVPA on weekdays (104 minutes) than weekend days (66 minutes). Time spent in MVPA decreased with age for both weekdays and weekend days. Children and young people spent 338 minutes per day in light physical activity, while the time spent in light activity increased with age (Clinical Trials Research Unit, 2010). Similar patterns were found among Australian children, averaging 117 minutes per day spent in physical activity. Boys were on average significantly $(p<$ 0.01) more active than girls by about 15 minutes per day (Spinks, Macpherson, Bain, \& 
McClure, 2006).

In contrast, at the present time children spend a large part of their free leisure time watching television or playing computer games (Hoos, Gerver, Kester, \& Westerterp, 2003). Children from the United States spent more than 10 hours each day in sedentary pursuits such as viewing television, sitting at the computer, and/or doing homework (Strauss et al., 2001). In New Zealand, only four of ten (39.4\%) of children and youth fulfilled the criteria of screen time guideline (i.e., less than two hours per day in front of television, computers, and gaming consoles; Clinical Trials Research Unit, 2010). In England, sedentary activity accounted for the largest amount of time (i.e., seven hours) for both sexes. Sedentary time on average was very similar for boys and girls on weekdays (i.e., 3.4 hours) and weekends (i.e., 4.15 hours). The average time spent in sedentary activities increased with age for both girls and boys (Craig et al., 2009). In Australia, a study found that approximately $15 \%$ of the children sampled were at risk for being insufficiently active according to Australian physical activity guidelines. These guidelines are in agreement with international recommendations. Nearly one in three children exceeded 2 hours per day in sedentary activities, such as watching television or using a computer for leisure (Spinks et al., 2006).

Overall children are spending less of their time in physical activity and more time in sedentary activity thereby contributing to the obesity epidemic and the health status of the world. Since the obesity rates have increased at an alarming rate, health associations and governments around the world have developed recommendations to increase physical activity to promote health. 


\section{Physical activity recommendations for children.}

In the United States, two important organizations have emphasized the important of physical activity for children, and have recommended physical activity guidelines. The National Association for Sport and Physical Education offers national recommendations for children (5 to 12 years of age) on physical activity. These guidelines are: (a) Children should engage in at least 60 minutes and up to several hours of daily, of age-appropriate physical activity on all, or most days of the week. This accumulative time should include moderate and vigorous physical activity with the majority of the activities being spent in activity that is intermittent in nature. (b) Children should engage in several bouts of physical activity lasting 15 minutes or more each day. (c) Each child should participate every day in a variety of age-appropriate physical activities designed to achieve optimal health, wellness, fitness, and performance benefits. (d) Extended periods of inactivity (two or more hours) are not recommended for children, especially during the daytime hours (National Association for Sport \& Physical Education, 2007).

In addition, U.S. Department of Health \& Human Services (HHS) listed physical activity guidelines for children and adolescents (6 to 17 years of age). These recommendations include: (a) Children and adolescents should do 60 minutes or more of

physical activity daily. (b) Most of the 60 or more minutes a day should be engaged in either moderate or vigorous intensity aerobic activities. (c) At least 3 days of the week should include vigorous-intensity activity. (d) Muscle- and bone-strengthening activities should be include as part of their 60 or more minutes of daily physical activity on at least 3 days of the week. (e) Young people should participate in physical activities that are appropriate for their age, that are enjoyable, and that offer variety (HHS, 2008). 
The American College of Sports Medicine proposes that children can accumulate physical activity with a mix of moderate and vigorous activity that can be performed continuously or intermittently (American College of Sports Medicine, 2009). The WHO (2010), European Union and several European countries (Oja, Bull, Fogelholm, \& Martin, 2010) and Australia (Spinks et al., 2006) have similar recommendations for 5 to 17 year olds and 5 to 12 year olds.

Furthermore, Tudor-Locke, MaClain, Hart, Sisson, and Washington (2009b) have recommended steps per day as the most appropriate metric choice to measure youth physical activity. According to Tudor-Locke (2002) the number of steps accumulated (average steps per day) by school students is higher when compared to adults. While sedentary adults accumulate 5,000 to 8,000 steps and more active adults range from 7,000 to 10,000 or more steps, children accrue 11,000 to 13,000 steps per day for boys and 10,000 to 11,000 steps per day for girls. Other studies in Australia (Cox, Schofield, Greasley, \& Kolt, 2005) and Sweden (Raustorp, Pangrazi, \& Stahle, 2004) suggest that these children accumulate more steps per day than children from the United States (Le Masurier et al., 2005; Vincent, Pangrazi, Raustorp, Michaud Tomson, \& Cuddihy, 2003). An international study using American, Australian, and Swedish children conducted by Tudor-Locke, Pangrazi, et al. (2004) established steps per day recommendations related to body mass index (BMI). The selected cut points for step per day for 6 to 12 year olds were 12,000 steps per day for girls and 15,000 steps per day for boys if the goal is maintenance of a healthy BMI. Vincent and Pangrazi (2002) found that steps accumulated by elementary school children do not differ by age or/and grade. Tudor-Locke, MaClain, Hart, Sisson, and Washington (2009a) suggested that during 
weekdays boys take approximately 12,000 to 16,000 steps per day, and girls accumulate between 10,000 to 14,000 steps per day. In contrast, during the weekend boys take 12,000 to 13,000 steps per day and girls take 10,000 to 12,000 steps per day. The 2001 2002 President's Challenge Physical Activity and Fitness Awards Program of the President's Council on Physical Fitness and Sports (2001) recommend that children accumulate at least 13,000 steps for boys, and 11,000 steps for girls per day (Corbin, Pangrazi, \& Le Masurier, 2004). Those initial pedometer recommendations were established using the mean steps per day data from available research (Vincent \& Pangrazi, 2002).

Implementing the physical activity guidelines should be followed to achieve health benefits. It is also important to consider the dimensions and determinant that are associated with physical activity so that more effective interventions to promote children's physical activity can be implemented. Those aspects will be discussed in the following section.

\section{Physical activity dimensions.}

Physical activity can be categorized in terms of dimensions. These include type, frequency, duration and intensity of the activity. According to Miles (2007) and WHO (2010), type of physical activity refers to the mode of participation (e.g. aerobic, strength, flexibility). Frequency refers to how often a person does physical activity, and is usually expressed in sessions, bouts or episodes. Duration refers to the length of time in which a person is performed an activity, and is generally expressed in minutes. Intensity refers to how hard a person works or the rate of energy expenditure that demands to do the activity. 
The U. S. Department of Health \& Human Services (2008) reported that intensity can be defined on an absolute (i.e. the rate of energy expenditure during the activity and is referred to as METS) or a relative scale (i.e. the person's level of cardiorespiratory fitness to assess level of effort). Both intensity methods (relative or absolute) are appropriate methods to track children's intensity activity (HHS, 2008). In adulthood activities are generally classified as light, moderate, and vigorous intensity on the basis of metabolic equivalents (METs). Because exercise energy expenditure per unit of body mass is higher in children and adolescents than in adults, these MET values have limitations (Strong et al., 2005). However, Pate, Pfeiffer, Trost, Ziegler, and Dowda (2004) proposed classifications or rates for physical activity for children. These recommendations include: (a) sedentary activity (1.4 METs), (b) light physical activity (1.5-2.9 METs), (c) moderate physical activity (3-5.9 METs), and (d) vigorous physical activity (6 METs or more). U. S. Department of Health \& Human Services (2008) suggests that children's guidelines can be met by mixing a combination of moderate and vigorous intensity activity, or by only do long vigorous-intensity activity. A child performs a moderate or vigorous activity based on absolute energy expenditure. For example, walking briskly and doing moderate-intensity activity results in feeling warm and slightly out of breath. Performing vigorous-intensity activity such as playing chase at a park will result in the body perspiring and breathing heavily.

Although there is limited evidence for children, it appears that the total amount of physical activity is more important for achieving health benefits than any one dimension (frequency, intensity, or duration) or specific mix of activities (aerobic, musclestrengthening, bone-strengthening) (HHS, 2008). This may be true, but many health 
benefits can occur with the increase of the intensity, frequency and/or duration of activity (Oja et al., 2010). Researchers have found an association between lower body fat with higher levels of vigorous intensity physical activity in children (Abbott \& Davies, 2004; Hussey, Bell, Bennett, O’Dwyer, \& Gormley, 2007; Ruiz et al., 2006).

\section{Children's physical activity determinants.}

Physical activity determinants are multifactorial with contributions from a variety of biological, environmental, psychological and sociological factors (Trost et al., 1997). Physical activity has a positive effect on growth and maturation in children. Although these biological factors might be difficult to change they are important to understand and take into consideration during investigations (Kohl III \& Hobbs, 1998).

Psychological and social determinants are more related with motivation, modeling, pressure and children's physical activity opportunities (Kohl III \& Hobbs, 1998). Hills and Byrne (2006) introduced some of the psychological barriers that obese children and adults report such as: poor experiences of physical activity, lack of selfefficacy, low self-esteem, low self-confidence, embarrassment, incorrect assumptions about how much physical activity to complete, soreness, and discomfort or pain as a result of exercise. These factors can also increase or decrease the intensity of physical activity and that is why it is important to have variation in the types of physical activity offered to children.

In Australia, Spinks, Macpherson, Bain, and McClure (2006) conducted a study to measure physical activity participation in a random sample of Australian primary school children. The aim of the study was to determine the major biological, behavioral, environmental and social influences on these patterns. According to their findings, 
participants who are involved in organized sports and activities were associated with sufficient activity. Children who spent more than 2 hours each day watching television or playing computer games were twice as likely to be insufficiently active as their counterparts, indicating that there is a time trade-off between these activities. The presence of outdoor play equipment in the home (e.g. swings, scooters, bicycles, and swimming pool) also appeared to influence sufficient activity although the relationship was not statistically significant. Furthermore, children from households with the lowest income spent significantly more time walking or cycling for transportation than children from the households with the highest income. However, there was no relationship found in age, family size, maternal education and socio-economic status (SES). In contrast Miles (2007) demonstrated that children from lower-income families had lower levels of physical activity levels (i.e., $66 \%$ of boys and $31 \%$ of girls, ages 2-10 years old).

Environmental influences can be especially relevant to children because they have less autonomy in their behavior choices (Ferreira et al., 2007). There are a lot of environmental determinants that moderate children's physical activity such as: lack of physical education and opportunities to move in schools; neighborhood design and safety; time spent watching television, playing computer games and surfing the internet as well as other sedentary entertainment; reduced time for play and time spent outdoors (Hills \& Byrne, 2006; Ferreira et al., 2007). Lack of safety, cross-cultural differences, crowding, social crime, traffic, air quality, access to sport and recreation facilities, and sidewalks have been identified as important barriers that influence children and youth's outdoor physical activity opportunities and choices (Giles-Corti, Kelty, Zubrick, \& Villanueva, 2009; Thompson, Rehman, \& Humbert, 2005). 
Another environmental determinant is associated with the school experience.

Kohl III and Hobbs (1998) suggested that modification of the school environment as well as seasonal and geographic factors can affect the activity levels of children substantially. Researches suggest that active transportation such as walking and/or cycling to and from school may contribute to higher levels of physical activity for children compared to those who travel to school by motorized transport (Cooper, Bo Andersen, Wedderkopp, Page, \& Froberg, 2005; Cooper, Page, Foster, \& Qahwaji, 2003). Mackett and Paskins (2008) found that walking is one of the best forms of children's physical activity because it requires no preparation, no special equipment, and no expenditure of money. Their findings suggest that children who walk to events tend to be generally more active than those children that use the car. The researchers also reported that children tend to be more active when they are playing outdoors than when they are in their homes. The Centers for Disease Control and Prevention (2005) reported in descending order of importance children's barriers to walking to school. These included distance to school, traffic danger, adverse weather conditions, crime danger, and opposing school policy.

As another environmental determinant on childhood behavior is parental influence. These mechanisms of influence can be either direct (e.g. providing support), indirect (e.g., through modeling) or an interaction of both (Ferreira et al., 2007). Additionally, children whose parents are physically active reported to be nearly six times more active than children whose parents are both inactive (Kohl III \& Hobbs, 1998; Ferreira et al., 2007). In addition to parental influences, social influences on physical behavior among children include role modeling (e.g. professional athletes) and peer pressure (Kohl III \& Hobbs, 1998). This parental influence can create a social, physical 
and emotional beneficial impact in developing their children physical activity behavior through their lives.

According to the ecological model, multiple levels of determinants (i.e., intrapersonal [biological, psychological], interpersonal [social, cultural], organizational, community, physical environmental, and policy) can play an influential role on physical behavior. This ecological model provides a comprehensive framework for understanding the multiple and interacting determinants of health behavior at several levels of influence. The model can be used to develop different mechanisms of change to intervene at each environmental level of influence (Sallis, Owen, \& Fisher, 2008). For example, a study conducted by Parley et al. (2007) reported that structural and conditioned aspects (e.g. schoolyard, play structure, sports equipment, organized physical activity programs, safe play space) in neighborhoods decrease or increase the levels of physical activity in children. Kohl III and Hobbs (1998) suggested that targeting environmental determinants is important with respect to reviewing and modifying existing physical education curricula, materials and teacher training. They also proposed to increase school sport programs that can provide opportunities for children to be physically activity. "Active Transport" such as travel by foot, bicycle, other non-motorized vehicles and/or using public transport has been identified as one strategy to increase physical activity levels (Mason, 2000). Based on these findings, outdoor play is a critical environmental determinant of children's physical activity, and should be investigated more closely.

\section{Outdoor Play and Public Health.}

Examining the role of outdoor play and activity as a viable solution for the decline in global health is a reasonable approach. Researchers realize the relationship between 
the amount of time spent outdoors and human health (Muñoz, 2009). There is evidence that green space in an urban environment can improve life expectancy and decrease health complaints. Much of this is thought to be due to a favorable environment for people to exercise (Bird, 2004). People who have access to more natural settings are healthier than other individuals (Kaplan \& Kaplan, 1989). In England, Mitchell and Popham (2007) demonstrated a positive association between the proportion of green space in an area and better health.

Evidence demonstrates that contact with nature has a positive impact on cholesterol, stress-reduction, blood pressure, and one's outlook on life (Hartig, Mang, \& Evans, 1991; Kaplan \& Kaplan, 1989; Leather, Pyrgas, Beale, \& Lawrence, 1998; Parsons, Tassinary, Ulrich, Hebl, \& Grossman-Alexander, 1998). A cross-sectional study involving 10,000 people from the Netherlands showed that living near green space created less health complaints and better mental and physical health than an urban environment (de Vries, Verheij, Groenewegen, \& Spreeuwenberg, 2003). Those with access to a garden, for example, have been shown to generally have fewer mental health problems (Pretty et al., 2007). A study from Denmark suggests that access to a garden or short distances to green spaces are associated with less stress and a lower likelihood of obesity (Nielsen \& Hansen, 2007).

This connection between spending time outdoors and wellbeing has been also explored (Korpela, Hartig, Kaiser, \& Fuhrer, 2001). Wellbeing is not just about physical fitness; it is also about spiritual, psychological, and the cultural aspects of the human being. This concept includes ideas like happiness, optimism, self-expression, self-esteem, quality of life, personal satisfaction with life and fitness to enjoy the freedom of outdoor 
exploration (Tabbush \& O’Brien, 2003). Douglas (2005) reported positive benefits in stress reduction, prevention of depression, wellbeing, and gains in mental and physical health by those individuals who were placed in urban or rural zones.

Outdoor exercise has been linked to positive health benefits and it is also been associated with greater overall levels of wellbeing and physical activity (Pretty et al., 2007). There is growing recognition that natural green space can increase levels of physical activity. Physical activity levels increase when participants have convenient and close contact to green space (Bird, 2004). Florez, Martinez, Chacra, Strickman-Stein, and Levis (2007) in a cross-sectional study suggested that outdoor exercise reduces the risk of vitamin D deficiency in overweight individuals.

The health benefits associated with outdoor experiences and physical activity are promising. Unfortunately, the majority of the physical activity research is implementing environmental and informative methods to develop policies to increase physical activity in children. There is a lack of information about the relationship between time spent in outdoor play and how this impacts environmental determinants in children's physical activity.

\section{Outdoor play and children's health.}

Children have been identified as one of the potential social groups that could gain health benefits from outdoor experiences (Nilsson, Baines, \& Konijnendijk, 2007). Children share many of the same health benefits that adults from outdoor use, however, there are some factors that are particularly more important with respect to children (Muñoz, 2009). According to Clements (2004) mothers recognize that the outdoor play provides a variety of opportunities for children to become more physically fit, increase 
their physical activity levels, and develop their fundamental motor skills. Another study suggested a relationship between versatile play in the natural environment and its impact on motor fitness in 5 to 7-year-old children's motor ability (Fjørtoft, 2001). There is evidence suggesting a relationship between active play, physical fitness, and body fatness in young children (Cleland et al., 2008; Goran, Reynolds, \& Lindquist, 1999).

Research suggests that children's contact with the natural environment provides them with the opportunity to interact with each other, understand the outer world and provides a crucial space to their developmental health (Louv, 2005; Valentine \& McKendrick, 1997). It is also suggested that a child who attends school that incorporates a large amount of time spent playing outdoors has fewer instances of non-attendance due to illness (Fjørtoft, 2001). Mannion, Sankey, Doyle, and Mattu (2006), and Senda and Kuwabara (2007) reports outdoors play and the use of natural features in educational settings can be beneficial for child and adolescent health. Children living in a place with more nature or restorative characteristics are more likely to benefit from his or her cognitive functioning (Wells, 2000). Mackett and Paskins (2008) found that British children who walk and play outside the home have higher levels of physical activity.

More specific, when children play outdoors a new world of sensory experiences will be open by touching dirt, water, sand, and mud, developing imaginative play or increasing the children's sense of adventure (Clements, 2004). In study conducted by Wells and Lekies (2006) indicated that participation in outdoor activities such walking, playing, hiking, camping, fishing, and more has a significant and positive association with later life outcomes (i.e., adults environmental attitudes and behaviors). 
Frost (2006) also associated physical activity within outdoor playgrounds to the development of "strength, flexibility and coordination" due to the types of activities facilitated by play equipment, such as "climbing", "balancing" and "swinging". Outdoor adventure activities have been shown to positively influence the attitudes, beliefs, confidence, and improve self-esteem, self-efficacy, physical self-image and fitness for children and youth (Rickinson et al., 2004). However, despite all these benefits children are spending less time outdoors.

\section{Children and the amount of time they spend outdoors.}

Research suggests that children are spending less time playing outdoors and the adult supervision in children outdoor play has increased (Fjørtoft, 2001; Karsten, 2005). Playing outside has lost is dominant features compared to 30 or more years ago, when children spent most of their time outdoors, each day of the week (Hofferth \& Sandberg, 2001). For example between 1981 and 1997 children's free playtime in the USA dropped by an estimated 25\% (Hofferth \& Sandberg, 2001). Today children play indoors, they go outside less frequently, and if they do go out to play, it is for short periods of time (Karsten, 2005). Children's play is increasingly becoming confined to places such as homes, bedrooms, basements or playrooms. And it appears that only a very small percentage of children in actuality have frequent exposure to natural green spaces (Fox, 2004; Kong, 2000; Valentine \& McKendrick, 1997). Kahn and Kellert (2002) reported that children have less direct contact with nature. They concluded that it is essential that the children have a direct and multiple contacts with nature for healthy development and maturation. Research has also shown the importance of childhood engagement with 
outdoor environments, as a significant life experience and a major contributor to adult perceptions and behaviors (Ward Thompson et al., 2008).

The International Play Association (Clements, 2005) reported that 40 percent of schools in the United States are abolishing recess or denying or reducing recess time to prepare for academic tests. Spontaneous outdoor play and children's engagement in outdoor play are becoming less prevalent. Collectively, research and experience indicate that a number of interrelated factors are contributing to the reduction of spontaneous, outdoor play. These include: substitution of spontaneous play and outdoor play for technology toys; parental fear of criminal activity against their children; lack of understanding of the value of outdoor play by parents, policy makers, and school officials; high stakes testing; playground safety standards; and lawsuits and threat of lawsuits (Frost, 2006).

Likewise, parent's opportunities to participate supervise and spend time outdoors with their children have decreased considerably (Children's Play Council, 2002; Little \& Wyver, 2008; Rivkin, 1995). In the United States, a study conducted by Clements (2004) explored the extent to which children in the United States actually played outdoors in comparison with their mother's experiences as children. A total of 830 mothers participated in the study. Findings showed that children (between the ages of 3 and 12) are clearly spending less time playing outdoors today than previous generation did as children. The researchers associated this decrease on dependence of television and digital media, concerns about crime and safety, lack of parent's time to spend outdoors with their children, and lack of adult supervision. However the majority of children reported that they would choose to engage in outdoor activities in the bush, in parks or on the 
beach (Tandy, 1999).

\section{Outdoor time, intensity and physical activity.}

Research has shown that encouraging primary school-aged children to engage in outdoor free play or unstructured physical activity contributes to their levels of physical activity (Burdette \& Whitaker, 2005). Bird (2004) suggests that when outdoors are associated with nature children increased their physical activity levels. When physical activity in young children was measured by direct observation, results suggest that time spent outdoors and prompts to be active were more correlated and highly associated with children's physical activity (Burdette, Whitaker, \& Daniels, 2004; Sallis et al., 1995).

A study conducted by Bell and Dyment (2006) examined the relationship between green school grounds and levels of physical activity at elementary schools across Canada. Results suggested that $49 \%$ of the respondents (i.e., parents, teachers, and administrators) indicated that green school grounds promoted more vigorous activity, and $71 \%$ reported that green school grounds resulted in more moderate and/or light levels of children's physical activity.

Studies have shown increases in levels of children's physical activity and decreases on sedentary time when school is conducted in outdoor setting (e.g. Forest Schools; Groves \& McNish, 2008; Lovell \& Roe, 2009). To date, there is one study supporting the relationship of outdoor intensity activity and children's physical activity. According to Clements (2004) more vigorous outdoor play activities help to promote children's physical abilities such as agility, power, flexibility, and cardiovascular fitness. Also, vigorous outdoor play activity can help relieve a child's stress and boredom. Evidence suggests that time after school spent outdoors significantly increased the time 
devoted to MVPA participation (Mota et al., 2008).

This association between time spent outdoors and physical activity suggests that outdoor play can increase children's physical activity levels, and promote health (Veitch et al., 2005). However, outdoors play and physical activity intensity is still not fully understood with respect to children's participation in physical activity.

Summary

The preceding literature review supports the association that physical activity is an important factor to combat the obesity epidemic, and promote health benefits and healthy lifestyle habits for children. Furthermore, the research reviewed support the notion that time in outdoor play is related to children's physical activity. The potential link between time spent outdoors and human health appears to be gaining more attention and interest among researchers and practitioners.

The purpose of this study was to examine the influence of time spent in outdoor play (i.e., on weekdays and weekend days) on daily (i.e., average steps count) and aerobic step count (i.e., moderate and vigorous [MVPA] on weekdays and weekend days) in fifth grade Costa Rican children. It was expected that children who spent more time in outdoor play would demonstrate a higher daily step count for the weekdays (Monday through Friday). It is also hypothesized that children who spent more time in outdoor play would demonstrate a higher step count for the weekend days. Children who spent more time in outdoor play would demonstrate a higher daily aerobic (MVPA) step count for the weekdays. Children who spent more time in outdoor play would demonstrate a higher daily aerobic (MVPA) step count for the weekend days. And boys would demonstrate a higher daily step count and daily aerobic (MVPA) step count during weekdays and 
weekend days when compared to girls. The following section will explain the methodology of this study. 


\section{Chapter III}

\section{Method}

The purpose of this study is to examine the influences of time spent in outdoor play on daily and aerobic step counts during the weekdays and weekend days in fifth grade Costa Rican children. This chapter presents the methodology for the study and consists of the following sections: (a) participants, (b) instruments, (c) procedures and design, and (d) data analysis.

\section{Participants}

The study population was selected from the province of San Jose. This region is composed of 20 counties and more than 1.6 million of Costa Rica's 4.5 million people lives in this region. The province of San Jose offers a large range of social classes, nationalities, physical features of neighborhoods and public schools. This region represents the heterogeneous population that resides in all of Costa Rican.

From the list of public schools (sampling frame) developed by the Costa Rican Ministry of Public Education, a total of three schools from the province of San Jose were selected to participate in this study, using probability sampling. Refer to Appendix A for descriptive information (Refer to Table 10) and the environmental context (Refer to Table 11) pertaining to each participating school.

All the fifth grade students enrolled in the three participating schools were invited to participate. Of the 403 possible participants, a total sample of 223 (55\%) fifth grade 
children was recruited to participate in this study. The sample size was determined using Cohen's power analysis (1992). Of those children who volunteered to participate, 195 $(87 \%)$ children had complete pedometer data that involved wearing the pedometer for 8 or more hours each day, and over 4 or more days (i.e. 3 or more weekdays and 1 or more weekend days). This criterion for inclusion of pedometer data was based on Vincent and Pangrazi (2002), and Kang et al. (2009) recommendations, that three to seven days of pedometer monitoring of physical activity in children, is appropriate. From 195 children, $3 \%$ (5) were eliminated from the data analysis due to missing data. Missing pedometer data in children is common and has been reported in previous studies (Rowe, Mahar, Raedeke, \& Lore, 2004; Vincent \& Pangrazi, 2002). A total of 190 children, ages 10 to 13 years, were included in the final analyses. A summary of descriptive information of the sample is presented in Table 2 participant's demographic information.

Approval from the Ministry of Public Education in Costa Rica, the school principals and the University Institutional Review Board for Human subjects was obtained. All participants returned an informed consent form (Refer to Appendix C for the letter to parent/guardian's consent form) signed by their parents, and children's signed assent (Refer to Appendix D for the minor assent form). 
Table 2

Participant's Demographic Information

Months Months

Participants $\quad n \quad$ Percentages

Min $\quad M(S D)$

\begin{tabular}{lccccc}
\hline Boys & 80 & $42 \%$ & 122 & 166 & $136.40(10.58)$ \\
Girls & 110 & $58 \%$ & 122 & 166 & $137.66(11.29)$ \\
Total & 190 & $100 \%$ & 122 & 166 & $136.93(10.87)$ \\
\hline
\end{tabular}

\section{Instruments}

\section{Outdoors play- Children's Outdoor Play Survey.}

Due to the lack of valid instruments to measure outdoor play, a Children's Outdoor Play Survey (Refer to Appendix B for the Children's Outdoor Play Survey) was developed. The researcher developed this survey, based on previous research in the field (such as Burdette et al., 2004; Cleland et al, 2008; Clements, 2004; Cordell, Bets \& Green, 2009; Page, Cooper, Griew, Davis, \& Hillsdon, 2009; Report to Natural England, 2009; Wen, Kite, Merom, \& Rissel, 2009). The Children's Outdoor Play Survey was created in English and was then translated to Spanish, to fulfill the native language of the Costa Rican Children. Various methods of validity and reliability were applied to this survey. Face validity and content validity were applied by utilizing expert reviews, native speaker reviewers (English and Spanish) and literature reviews. To refine the instrument a pilot test was performed. A total of 96 Spanish-speaking children completed the survey and provided feedback. Time spent outdoors, and demographic information are 
components of the Children's Outdoor Play Survey.

Two items were modified based on the pilot test and the instrument refinement phase. The first item modified related to how many days of the week the child participated in a variety of outdoor activities. This item included a 0 to 7 scale. Many of the children reported that they did not understand the scale associated with this item on the questionnaire. New sets of questions were developed to clarify the question. This item included outdoor activity intensity (i.e., light, moderate and vigorous) for weekdays and weekend days, and an outdoor activity participation list. The second item on the survey that was identified as confusing by the pilot participants, dealt with the number of siblings. Children had a difficult time with the options provided for this on the survey. In the revised item, the instruction was modified and the options were rearranged.

\section{Time spent outdoors.}

The Children's Outdoor Play Survey contains two items that ask students to recall during the last week, how much time they spent outdoors for a weekday and a weekend day. The child is asked to select one time slot out of seven incremental options ranging from zero to four or more hours. Each interval ranges from a half an hour for the first hour, and then after one or more hours the intervals consists of one-hour segments. An average time per day spent playing outdoors during a weekday and a weekend day was tabulated. From those intervals three groups was created: (a) Group 1 "less than 1 hours", (b) Group 2 "between 1 hour to 2:59 minutes" and, (c) Group 3 "3 or more hours" of time spent playing outdoors per day. This grouping was based on the results obtained during the administration of the survey to the pilot participants. Table 3 presents the descriptive data for the pilot test sample and the study sample by group. 
Table 3

Reported Percentages of Time in Outdoor Play from Pilot Test Sample and the Study Sample by Group

\begin{tabular}{lcccc}
\hline \multicolumn{1}{c}{ Groups } & \multicolumn{2}{c}{ Pilot test } & \multicolumn{2}{c}{ Study } \\
\cline { 2 - 5 } & $n$ & Percentages & $n$ & Percentages \\
\cline { 2 - 5 } Less 1 hour & 21 & $22 \%$ & 42 & $22 \%$ \\
Between 1 o 2:59 min & 33 & $34 \%$ & 72 & $38 \%$ \\
3 or more hours & 42 & $44 \%$ & 76 & $40 \%$ \\
Total & 96 & $100 \%$ & 190 & $100 \%$ \\
\hline
\end{tabular}

\section{Demographic information.}

Demographic information was collected from the Children's Outdoor Play Survey, which includes sex, date and country of birth, and number of siblings.

\section{Physical activity - Pedometers.}

Researchers have used a range of different measurement tools and protocols in both laboratory and field studies to measure physical activity. These tools are commonly divided into objective (e.g. doubly labeled water (DLW), direct observation, heart rate, monitoring, and motion sensors such as accelerometers and pedometers) and subjective methods (e.g. questionnaires) (Hands \& Larkin, 2006; Hussey, Bell, \& Gormley, 2007; Sirard \& Pate, 2001).

Motion sensors have gained credibility in physical activity research with children. One kind of motion sensor is the pedometer. This particular measurement records in steps the acceleration and deceleration of the waist in the vertical direction (Hussey, Bell, \& 
Gormley, 2007), and provides valid assessment of the total volume of physical activity. Pedometers are easy to use, inexpensive, re-usable, objective, nonreactive, and are ideally suited to large-scale studies. According to the findings of Hands and Larkin's study (2006), there was a higher correlation between pedometer and direct observation measurement than with the accelerometer when engaged in recreational activities and classroom activities for participant's ages 5 to 6 years. A pedometer is a better measure of physical activity in young children when engaged in a variety of free play activities compared to the accelerometer (Hands \& Larkin, 2006). This instrument reports correlations between .73 and .79 for 3 to 4 days of monitoring (Hands \& Larkin, 2006). Children's daily step count and aerobic step count in this study was measured using the Omron HJ-720 ITC pedometer. This is an electronic monitor that records step counts on both vertical and horizontal planes. This device offers many advantages such as can be worn either in a pocket or clipped to a belt, records and stores information in its memory for 42 days, resets automatically at midnight, and cannot be zeroed manually. Other advantages for the monitor is that it measures the dimension of intensity (aerobic steps, achieved at moderate intensity level $=3$ METs), and records the amount of time spent in moderate-to-vigorous physical activity. A 20-steps field test was conducted to validate that the pedometers worked appropriately and to assess measurement error. The pedometer was calibrated for each child (stride length and weight) and each participant was given verbal instructions on how to wear and use the pedometer. Figure 1 illustrates how the participants wore the pedometer. This pedometer has been tested for validity in prescribed and self-paced walking and demonstrates an absolute percent error of $<3.0 \%$ (Holbrook, Barreira, \& Kang, 2009). 


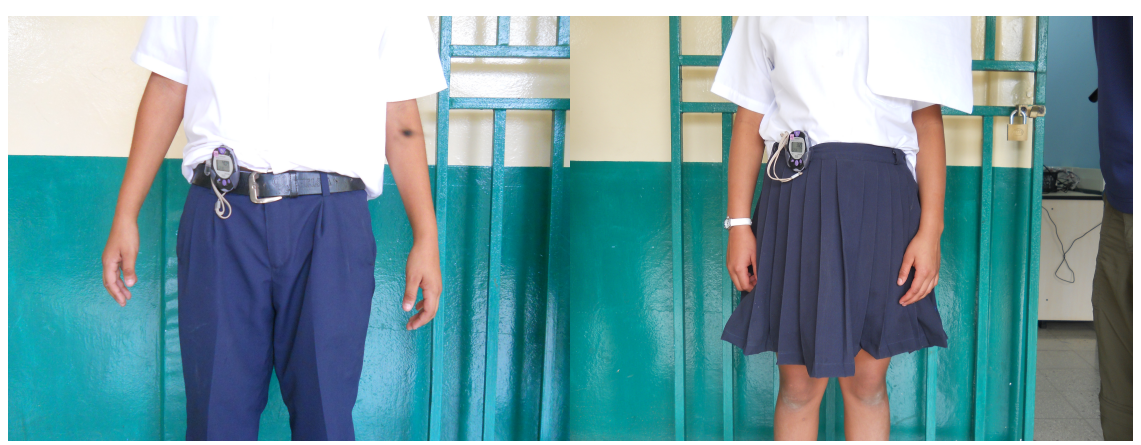

Figure 1. Photograph of participants wearing the pedometer.

Evidence supports the use of pedometer step count as a measure of physical activity in children. Le Masurier et al. (2005) showed that pedometers determined physical activity levels for youth. Barfield, Rowe, and Michael (2004) determined a high interinstrument reliability in the assessment of step counts in school children across conditions, such as class, recess, and physical education time. Beighle and Pangrazi (2006) used a pedometer to describe the daily steps and activity time of elementary school age children and the relationship between these measures. Groves and McNish (2008), and Lovell and Roe (2009) showed the potential of using pedometers as a way of measuring children's activity levels during outdoor play. Tudor-Locke, MaClain et al. (2009b) recommended that steps per minute could be used to interpret time intensity in specifically delimited time periods such as physical education class and recess. They also reported pedometer intraclass correlations for 8 days (.87), over 2 days (.65), weekdays (.75), vacations days (.69), school days (.74) and weekend days (.59). The Omron HJ-720 ITC pedometer reports the total steps that a child takes per hour and does not report steps per minute. In this study an average step count and an average aerobic step count during weekdays and weekend days were tabulated.

Furthermore, A study made by Scruggs et al. (2003) supported the use of 
pedometry steps per minute values as an accurate indicator of moderate to vigorous physical activity in physical education. These studies stress the benefits of using such monitoring devices in terms of the accuracy in recording physical activity.

\section{Procedure}

As soon as the schools were selected, a letter of parent/guardian's consent (Refer to Appendix C) was sent to all the fifth grade children. If there are parents who do not return the consent document in the first two days, a reminder letter and the letter of parent's consent were redistributed. After 2 days have passed from the second reminder submission another reminder was sent to the child's home, if the form was not been returned.

When the letters of consent and the children's assent form (Refer to Appendix D) were returned to the teacher with appropriate signatures, the researcher measured the stride length, weight and height to all children (with parental consent and children's assent approved by Auburn University IRB for Human Subjects). As soon as the fifth grade children completed the stride length and weight measurements, pedometer measurements were calibrate to objectively measure physical activity.

The Omron HJ-720 ITC pedometer was distributed by the researchers to each child and asked to wear it for one week (five week days and two weekend days) during waking hours. Each child received a demonstration and explanation on how to wear the monitor and how and when to remove it (i.e., only during showering, bathing, swimming or sleeping). At the end of the week the researcher collected the pedometers from the children. The same day that pedometers were collected, the researcher administered the survey to all children (who wore the pedometer for a week), in their regular classrooms at 
the same time, and in the presence of their regular teacher. (Refer to Appendix B for survey general instructions.) Table 4 presents the schedule that was used for data collection.

Table 4

Schedule for Data Collection

\begin{tabular}{|c|c|}
\hline Week & Activity \\
\hline First week & Gathering the parental consents and children's assents. \\
\hline \multirow[t]{4}{*}{ Second week } & M/T = School 1- Measure children's stride length. \\
\hline & $\mathrm{W}=$ Send out first set of pedometers (school 1). \\
\hline & $\mathrm{R}=$ School 2 - Measure children's stride length. \\
\hline & $\mathrm{F}=$ Send out second set of pedometers (school 2). \\
\hline \multirow[t]{5}{*}{ Third week } & M = School 3 - Measure children's stride length. \\
\hline & $\mathrm{T}=$ School 3 - Measure children's stride length. \\
\hline & W = Pick up first set pedometers. Administer children's survey. \\
\hline & $\mathrm{R}=$ Send out third set of pedometers (school 2). \\
\hline & $\mathrm{F}=$ Pick up second set pedometers. Administer children's survey. \\
\hline \multirow[t]{2}{*}{ Forth week } & $\mathrm{T}=$ Send out forth set of pedometers (school 3). \\
\hline & $\mathrm{R}=$ Pick up third set pedometers. Administer children's survey. \\
\hline \multirow[t]{2}{*}{ Fifth week } & $\mathrm{M}=$ Send out fifth set of pedometers (school 3). \\
\hline & $\mathrm{T}=$ Pick up forth set pedometers. Administer children's survey. \\
\hline Sixth week & $\mathrm{M}=$ Pick up fifth set of pedometers. Administer children's survey. \\
\hline
\end{tabular}




\section{Data Analysis}

Data was subjected to 4, 2 X 3 factorial ANOVAs with alpha set a priori at .05 . These factorial ANOVAs compared the effect of multiple independent variables on one dependent variable. In this study the factorial ANOVAs examined whether interaction or main effects existed between sex and time spent playing outdoors during the weekdays and weekend days for daily step count and daily aerobic step count (MVPA).

Of the four ANOVAs, two were conducted to address the research hypotheses associated with daily step count: children who spent more time in outdoor play would demonstrate a higher daily step count during weekdays, children who spent more time in outdoor play would demonstrate a higher daily step count over the weekend days, and boys would demonstrate a higher daily step count and daily aerobic (MVPA) step count during weekdays and weekend days than girls. Time spent playing outdoors and the variable Sex served as the independent variables, and daily average step count during weekdays and weekend days were the dependent variables.

The other two ANOVAs were conducted to address the research hypotheses associated with aerobic step count. These hypotheses predicted that: (a) children who spent more time spent in outdoor play would demonstrate a higher daily aerobic step count during weekdays, (b) children who spent more time spent in outdoor play would demonstrate a higher daily step count over the weekend days, and (c) boys would demonstrate a higher daily step count and daily aerobic (MVPA) step count during weekdays and weekend days than girls. Time spent playing outdoors (Groups) and the variable, Sex, served as the independent variables, and daily aerobic step count during weekdays and weekend days were the dependent variables. 
For the four ANOVAs, the first factor was sex (boys vs. girls) and the second factor was time spent in outdoor play (Group 1, Group 2, and Group 3). Children's time spent playing outdoors for both weekdays and weekend days were classified as: Group 1 "less than 1 hour", Group 2 "between 1 hour and 2:59 minutes", and Group 3 "3 hours or more". In the event a significant main effect emerged, a pairwise comparison follow-up was conducted to determine which groups differed. When a significant interaction between variables was established, a follow-up one-way ANOVA was conducted for each condition.

Data screening and analyses were conducted using Microsoft Excel and SPSS, version 18.0 (SPSS, Inc., Chicago, IL). Prior to conducting the analyses, frequencies were run on all data to screen for data errors, or outliers. Daily step counts below 1,000 and above 30,000 steps were chosen as the criteria for eliminating outliers based on the cut-off points made by Rowe, Mahar, Raedeke, and Lore (2004). Throughout the data screening, five children's data were not included in the analyses and treated as missing data, because they did not meet the criteria. 


\section{Chapter IV}

Results

The purpose of this study was to examine the influence of time spent in outdoor play (i.e., on weekdays and weekend days) on daily (i.e., average steps count) and aerobic step count (i.e., moderate and vigorous [MVPA] on weekdays and weekend days) in fifth grade Costa Rican children. It was hypothesized that (a) children who spent more time in outdoor play (as measured by item \#6 in the Children's Outdoor Play Survey) would demonstrate a higher daily step count for weekdays (Monday through Friday), (b) children who spent more time in outdoor play (as measured by item \#7 in the Children's Outdoor Play Survey) would demonstrate a higher daily step count for the weekend days, (c) children who spent more time in outdoor play (as measured by the Children's Outdoor Play Survey) would demonstrate a higher daily aerobic (MVPA) step count for the weekdays, (d) children who spent more time in outdoor play (as measured by the Children's Outdoor Play Survey) would demonstrate a higher daily aerobic (MVPA) step count for the weekend days, and (e) boys would demonstrate a higher daily step count and daily aerobic (MVPA) step count during weekdays and weekend days when compared to girls.

The following chapter presents results of the current study and includes the following: descriptive statistics of the participants, and two additional sections (a) daily pedometer step count for the weekdays and weekend days and (b) aerobic step count for 
the weekdays and weekend days. Sex differences are reported within these two sections. Descriptive statistics for height (centimeters) and weight (pounds) means $(M)$ and standard deviation $(S D)$ can be found in Table 5 for the participants' height and weight means and standard deviations by age and sex.

Table 5

Participant Height and Weight Means and Standard Deviations by Age and Sex

\begin{tabular}{|c|c|c|c|c|c|c|}
\hline \multirow[t]{2}{*}{ Age } & \multirow[t]{2}{*}{ Sex } & \multirow[t]{2}{*}{$n$} & \multicolumn{2}{|c|}{ Height (cm.) } & \multicolumn{2}{|c|}{ Weight (lbs) } \\
\hline & & & $M$ & $S D$ & $M$ & $S D$ \\
\hline \multirow{2}{*}{10} & $\mathrm{~F}$ & 47 & 140.87 & 7.55 & 85.84 & 27.54 \\
\hline & M & 30 & 137.06 & 5.02 & 74.39 & 14.80 \\
\hline \multirow{2}{*}{11} & $\mathrm{~F}$ & 36 & 140.61 & 16.38 & 93.78 & 27.16 \\
\hline & M & 29 & 139.60 & 6.27 & 79.24 & 17.11 \\
\hline \multirow{2}{*}{12} & $\mathrm{~F}$ & 18 & 148.24 & 7.96 & 93.25 & 20.65 \\
\hline & M & 13 & 146.92 & 5.81 & 94.35 & 23.84 \\
\hline \multirow{2}{*}{13} & $\mathrm{~F}$ & 9 & 147.88 & 5.78 & 89.73 & 14.44 \\
\hline & M & 8 & 158.50 & 11.40 & 123.72 & 35.47 \\
\hline \multirow{2}{*}{ Total } & $\mathrm{F}$ & 110 & 142.57 & 11.52 & 89.97 & 25.55 \\
\hline & M & 80 & 141.73 & 9.10 & 84.34 & 24.55 \\
\hline
\end{tabular}




\section{Daily Pedometer Step Count for Weekdays and Weekend Days}

\section{Average Step count for Weekdays.}

The 2 (Sex) x 3 (Groups) ANOVA to investigate time spent in outdoor play and sex on daily step count during weekdays showed a statistically significant main effect for Groups (time playing outdoors) on daily average step count for the weekdays, $F(2,184)=$ 4.106, $\eta 2=.043, p=.018$. (Refer to Table 8 ). A statistically significant main effect for Sex was also found $F(1,184)=8.600, \eta 2=.045, p=.004$ (Refer to Table 8). The mean differences revealed that daily average step count during weekdays was significantly lower for girls $(M=9503.62, S D=2735.39)$ than for boys $(M=11,261.21, S D=$ 3989.69; Refer to Table 7 for the weekdays and weekend days average step count and aerobic step count means and standard deviations for males and females.) No statistically significant interaction between Groups (time spent in outdoor play) and Sex on daily step count for weekdays was found, $F(2,184)=.975, p>.05$ (Refer to Table 8).

In order to identify which pairs of means significantly differed statistically for time spent in outdoor play for weekdays a follow-up analysis was conducted. Post hoc analyses using the Bonferroni post hoc criterion for significance indicated that the daily average step count was significantly lower for Group 1 (i.e., less than 1 hour) $(M=$ 9052.91, $S D=2468.86)$ than for Group 3 (i.e., 3 hours or more) $(M=10,905.54, S D=$ $3792.42), F(2,184)=4.106, p=.018$. However, there was no group difference between Group 1 and Group 2, and Group 2 and Group 3. (Refer to Table 6 for the weekdays and weekend days average step count and aerobic step count means and standard deviations for time spent playing outdoors.) 
Table 6

Weekdays and Weekend Days Average Step Count and Aerobic Step Count Means and Standard Deviations for Time Spent Playing Outdoors

\begin{tabular}{|c|c|c|c|c|c|c|}
\hline \multirow[t]{2}{*}{ Daily Counts } & \multicolumn{2}{|c|}{ Less than 1 hour } & $\begin{array}{l}\text { Betwee } \\
2: 59 n\end{array}$ & $\begin{array}{l}1 \text { and } \\
\text { nutes }\end{array}$ & \multicolumn{2}{|c|}{3 hours } \\
\hline & $M$ & $S D$ & $M$ & $S D$ & $M$ & $S D$ \\
\hline $\begin{array}{l}\text { Average step } \\
\text { count Weekdays }\end{array}$ & $9052.91 *$ & 2468.86 & $10,239.62$ & 3345.61 & $10,905.54^{*}$ & 3792.42 \\
\hline $\begin{array}{l}\text { Average step } \\
\text { count Weekend }\end{array}$ & 8070.80 & 3245.10 & 8853.48 & 4519.11 & 8636.42 & 4108.79 \\
\hline $\begin{array}{l}\text { Aerobic step } \\
\text { count Weekdays }\end{array}$ & 1440.77 & 1264.32 & 1775.75 & 1567.61 & 1602.06 & 1167.59 \\
\hline $\begin{array}{l}\text { Aerobic step } \\
\text { count Weekend }\end{array}$ & 1319.26 & 1524.42 & 934.12 & 1463.76 & 1197.40 & 1378.29 \\
\hline
\end{tabular}

*The mean difference is significant at the .05 level

\section{Average Step count for Weekends Days.}

The 2 (Sex) x 3 (Groups) ANOVA indicated that there was a main effect for Sex on daily average step count for weekend days $F(1,184)=4.873, \eta 2=.026, p=.029$. (Refer to Table 8). Mean differences indicate that daily average step count for weekend days was significantly lower for girls $(M=7946.60, S D=3505.20)$ than for boys $(M=$ 9412.71, $S D=4567.59$ ). (Refer to Table 7 the means and standard by sex.) The results of the two way ANOVA showed that there was no Group main effect for time spent playing 
outdoors on daily average step count for weekend days, $F(2,184)=.714, p>.05$. (Refer to Table 8). No significant interaction was found between Groups (time spent in outdoor play) and Sex for daily step count for the weekend days $F(2,184)=.556, p>.05$. (Refer to Table 8). A summary of means and standard deviations for time spent playing outdoors during the weekend days are provided in Table 6 .

Table 7

Weekdays and Weekend Days Average Step Count and Aerobic Step Count Means and Standard Deviations for Males and Females

\begin{tabular}{ccccc}
\hline \multirow{2}{*}{ Daily } & \multicolumn{2}{c}{ Male } & \multicolumn{2}{c}{ Female } \\
\cline { 2 - 5 } & $M$ & $S D$ & $M$ & $S D$ \\
\hline Average step count Weekday & $11,261.21^{* *}$ & 3989.69 & 9503.63 & 2735.39 \\
Average step count Weekend & $9412.71^{*}$ & 4567.59 & 7946.60 & 3505.20 \\
Aerobic step count Weekday & $2027.58^{* *}$ & 1566.05 & 1344.70 & 1092.10 \\
Aerobic step count Weekend & $1470.41^{*}$ & 1622.94 & 909.70 & 1250.61
\end{tabular}

* The mean difference is significant at the .05 level

**The mean difference is significant at the .01 level

\section{Aerobic Pedometer Step Count for Weekdays and Weekend Days}

\section{Average Aerobic Step Count for Weekdays.}

The 2 (Sex) x3 (Group) ANOVA revealed that there a main effect of sex on daily aerobic step count for weekdays, $F(1,184)=11.105, \eta 2=.057, p=.001$. (Refer to Table 8). According to the group mean differences daily aerobic step count for the weekdays was significantly lower for girls $(M=1344.70, S D=1092.10)$ than for boys $(M=$ 2027.58, $S D=1566.05$.) (Refer to Table 7 for the means and standard by sex.) The 
results indicated no Group main effect of time spent playing outdoors on daily aerobic step count on weekday, $F(2,184)=.804, p>.05$. (Refer to Table 8$)$. No interaction effect between Groups (time spent in outdoor play) and $\operatorname{Sex}, F(2,184)=.070, p>.05$, was found. (Refer to Table 8). A summary of means and standard deviations for time spent playing outdoors during the weekdays are provided in Table 6.

\section{Average Aerobic Step Count for Weekends Days.}

The 2 (Sex) x3 (Groups) ANOVA showed that there was a main effect of Sex on daily aerobic step count for weekend days, $F(1,184)=6.012, \eta 2=0.32, p=.015$. (Refer to Table 8$)$. According to the group mean differences girls $(M=909.70, S D=1250.61)$ had significantly lower daily aerobic step count than boys $(M=1470.41, S D=1622.94$. $)$ (Refer to Table 7 for the means and standard by sex.) The results indicated no main effect for time spent playing outdoors on daily aerobic step count for the weekend days, $F(2$, $184)=.778, p>.05$. (Refer to Table 8$)$. The omnibus test also yielded no statistically significant interaction effect between Groups (time spent in outdoor play) and Sex, $F(2$, $184)=.197, p>.05 .($ Refer to Table 8$)$. A summary of the mean and standard deviation for time spent playing outdoors during the weekend days are provided in Table 6. 
Table 8

F values on Time Spent Playing Outdoors Group and Sex Main Effects and Interactions for the dependent variables

\begin{tabular}{lcccccc}
\hline \multirow{2}{*}{ Dependent variables } & \multicolumn{2}{c}{ Group effect } & \multicolumn{2}{c}{ Sex effect } & \multicolumn{2}{c}{ Interaction effect } \\
\cline { 2 - 7 } & $F(p)$ & eta $^{2}$ & $F(p)$ & eta $^{2}$ & $F(p)$ & eta $^{2}$ \\
\hline Average step count & 4.106 & .043 & 8.600 & .045 & .975 & .010 \\
Weekday & $(0.018)^{*}$ & & $(.004)^{* *}$ & & $(.379)$ & \\
Average step count & .714 & .008 & 4.873 & .026 & .556 & .006 \\
Weekend & $(.491)$ & & $(.029)^{*}$ & & $(.574)$ & \\
Aerobic step count & .804 & .009 & 11.105 & .057 & .070 & .001 \\
Weekday & $(.449)$ & & $(.001)^{* *}$ & & $(.933)$ & \\
Aerobic step count & .778 & .008 & 6.012 & .032 & .197 & .002 \\
Weekend & $(.461)$ & & $(.015)^{*}$ & & $(.822)$ & \\
\hline
\end{tabular}

$p^{*}<0.05 * *<0.01$ 


\section{Chapter V}

\section{Discussion}

The purpose of this study was to examine the influence of time spent in outdoor play (i.e., on weekdays and weekend days) on daily (i.e., average step counts) and aerobic step count (i.e., moderate and vigorous [MVPA] on weekdays and weekend days) in fifth grade Costa Rican children. This chapter presents a discussion of the results for this study, and consists of the following sections: (a) hypotheses findings, (b) summary, and (c) conclusions and future research recommendations.

\section{Hypothesis Findings}

\section{Average Step count for Weekdays.}

It was hypothesized that children who spent more time in outdoor play (as measured by item \#6 in the Children's Outdoor Play Survey) would demonstrate a higher daily step count for weekdays. The hypothesis was partially supported. The results of this study indicate that children who spent three hours or more in outdoor play generate higher daily step counts on weekdays than children who spend less than one hour outdoors. This result supports previous findings that have shown an association between time spent outdoors and physical activity. Veitch Bagley, Ball, \& Salmon (2005) found that outdoor play can increase children's physical activity levels, and promote health. A study on primary school-aged children showed that encouraging children to engage in outdoor free play contributes to their levels of physical activity (Burdette \& Whitaker, 
2005). Bird (2004) suggested that when outdoors are associated with nature children increased their physical activity levels. Other studies showed that time spent outdoors with prompts to be active were more correlated and highly associated with children's physical activity (Burdette, et al., 2004; Groves \& McNish, 2008; Lovell \& Roe, 2009; Sallis et al., 1995).

This influence of time spent in outdoor play on daily step count was statistically significant between Group 1 (i.e., less than 1 hour) and Group 3 (i.e., 3 hours or more). This finding suggests that increasing the time from 1 hour to 3 hours or more of outdoor play may contribute significantly to the overall daily step count for fifth grade children in Costa Rica. This may also help in the attainment of recommended levels of weekly outdoor physical activity for children living in climate conditions that allow them to be outdoors all year long. Three or more hours in outdoor play would results in more weekday daily step counts for children. However, since there were no statistical differences between Groups 1 and 2, and 2 and 3, it appears that other factors are playing an influential role into the relationship between time spent outdoors and physical activity, such as independent mobility, BMI, and social economic status. Further research is needed to better understand the influence of these variables on outdoor physical activity.

The finding that boys generated a significantly higher daily step count during the week when is compared to girls has important public health implications, since this is the first study that objectively measured physical activity levels in Costa Rica children. The mean differences revealed that daily average step count for the weekdays was significantly lower for girls than for boys. The girls averaged 1758 fewer pedometer step counts per day than boys. A similar result was found during the weekend days. Girls on 
average accumulated 1466 fewer steps count per day than boys. A total of 11,722 fewer steps for the average female for the full week (7 days) when compared to the average male. Several studies have found similar differences between the two sexes (Beighle \& Pangrazi, 2006; Johnson, Brusseau, Graser, Darst, \& Kulinna, 2010; Hussey, Bell, Bennett, et al., 2007; Le Masurier et al., 2005; Purslow, Hill, Saxton, Corder, \& Wardle, 2008; Tudor-Locke, Johnson, \& Katzmarzyk, 2010; Tudor-Locke, Lee, Morgan, Beighle, \& Pangrazi, 2006). These finding support the hypothesis that boys acquired a higher daily average step count than girls over the week. It also suggests that government and health authorities in Costa Rica needs to explore ways to promote physical activity for girls, so that effective interventions can be implemented to improve their physical activity levels. Strategies and policies are needed to prevent sedentary behavior and combat inactivity in the female population in Costa Rican.

\section{Average Step count for Weekend Days.}

It was hypothesis that children who spent more time in outdoor play (as measured by item \#7 in the Children's Outdoor Play Survey) would demonstrate a higher daily step count for the weekend days. The results of this study suggest no statistically significant differences between time spent in outdoor play and step count for the weekend days.

One possible explanation for these results is that children in Costa Rica may be are less active during the weekend because they may spend more time in their homes; they have more parental influence and more chores. Researchers have reported that children tend to be more active when they are playing outdoors than when they are in their homes (Mackett \& Paskins, 2008). Studies also suggest that parents influence childhood behavior. These mechanisms of influence can be either by providing support, 
through modeling or an interaction of both (Ferreira et al., 2007). Likewise, parent's opportunities to participate, supervise and spend time outdoors with their children have decreased considerably (Children's Play Council, 2002; Little \& Wyver, 2008; Rivkin, 1995). The children in the present study reported that their parents spent time playing outdoors with them. However from a total of 152 children, $126(83 \%)$ of the children mentioned that their parents "seldom" or "some what" spent time playing outdoors, and only $17 \%$ of the children reported that their parents "often" or "always" spent time with them playing outdoors. Parental involvement may be one of the primary factors associated with Costa Rican children's outdoor activity on the weekends.

Additionally, Clements (2004) suggested that the decrease of children spending time outdoors is associated with television and digital media, lack of parent's time to spend outdoors with their children, and lack of adult supervision. Studies have found that children whose parents are physically active reported to be nearly six times more active than children whose parents are both inactive (Ferreira et al., 2007; Kohl III \& Hobbs, 1998). Further investigation is necessary to explore the relationship between parental influence and children spending time outdoors.

Another explanation for the lack of significant findings between time spent outdoors and average step count for weekend days, may be attributed to a lack of facilities or safe environments to play outdoors. Recent studies have shown an associated between decrease in time playing outdoors and parental fear of criminal activity against their children, and lack of safety (Clements, 2004; Frost, 2006). Studies also have reported that structural and conditional aspects such as access to sport, outdoor school environments and recreation facilities, and sidewalks have been identified as important 
determinants that influence children's outdoor physical activity opportunities and choices (Giles-Corti, et al., 2009; Haug, Torsheim, Sallis, \& Samdal, 2010; Parley et al., 2007; Thompson, et al., 2005). During the weekdays Costa Rican children spend half of the day or more at their school, which allows the opportunity to have a safety environment to play and be more active. It could be that during the weekend days Costa Rica children do not have safe environments to go outside and play.

Another viable explanation for why the average step count was lower over the weekend is that the children were not walking or cycling to school on those days. Although not measured, researchers observed, during data collection that most of the Costa Rican children used "active transportation", such as walking, bicycling or public transportation to travel to the school, instead of being delivered in a car. Studies have found that children who use active transportation to and from school present higher levels of physical activity compared to those who travel to school by motorized transport form home. These studies also suggest that children who walk to events tend to be generally more active than those children that use a car (Cooper, Bo Andersen, et al., 2005; Cooper, Page, et al., 2008).

Another potentially contributing factor to higher step counts over the weekdays as opposed to the weekend days is that the children received recess and physical education while attending school. In Costa Rica most of the schools have a mixed schedule, which means children go to the school half of the day (i.e., three days during the morning and two days during the afternoon). During that time they have at least 30 minutes per day of recess to engaged in unstructured free play. The three schools in this study provided physical education classes to their fifth grade students. Studies suggest that physical 
education class and recess promote engagement in more daily step count (Beighle, Morgan, Le Masurier, \& Pangrazi, 2006; Brusseau et al., 2011; Scruggs, 2007).

The means show that males in Costa Rica averaged 11,261 steps and 9504 steps for females for the weekdays, and 9413 (males) and 7947 (females) steps for the weekend days. The differences in weekdays and weekend days step count found in the present study of Costa Rican children are similar to those reported by Tudor-Locke, MaClain, et al. (2009a). Tudor-Locke and colleagues found that children accumulated more steps during the weekdays (boys approximately 12,000 to 16,000 steps per day; girls between 10,000 to 14,000 steps per day), than during the weekend days (boys perform 12,000 to 13,000 steps per day; girls perform 10,000 to 12,000 steps per day). However, further research is necessary to understand why Costa Rican children are less active over the weekend than the weekdays.

Another important finding of the present study is that there are not many children meeting the United States step count recommendation made by Tudor-Locke, Pangrazi, et al. (2004) established steps per day recommendations related to body mass index (BMI). The selected cut points for step per day for 6 to 12 year olds were 12,000 steps per day for girls and 15,000 steps per day for boys. According to Tudor-Locke, Johnson, et al. (2010) boys should take around 13,000 steps and girls around 12,000 per day. Similar total step per day was reported by Beighle and Pangrazi (2006) with 13,348 steps for boys and 11,702 steps for girls. Le Masurier et al. (2005) reported that boys accumulated 13,631 steps and girls accumulated 11,125 steps. Johnson, Brusseau, Graser, Darst, and Julinna (2010) reported 12,853 steps for boys and 10,409 steps for girls. In this study only $25.8 \%$ (boys $11.1 \%$, girls $14.7 \%$ ) and $20.5 \%$ (boys $11.1 \%$, girls $9.5 \%$ ) of the 
children are meeting the United States recommended number of step counts during the weekdays and weekend days, respectively. There are more boys $(26.3 \%$ in both weekdays and weekend days) meeting the recommendation than girls (25.5\% in weekdays and $16.4 \%$ in weekend days), but the percentages are low for both sexes. A summary of the outdoor activities reported by children who are met the step count recommendations is presented in Appendix E. Although these findings cannot be generalized to all the children in Costa Rica, they are providing important results for future intervention and further investigation in this country.

\section{Aerobic Pedometer Step Count for Weekdays and Weekend Days.}

It was hypothesized that children who spent more time in outdoor play (as measured by the Children's Outdoor Play Survey) would demonstrate a higher daily aerobic (MVPA) step count for the weekdays and for the weekend days. According to Clements (2004) more vigorous outdoor play activities help to promote children's physical abilities such as agility, power, flexibility, and cardiovascular fitness. Also, vigorous outdoor play activity has been shown to relieve children's stress and boredom. There is evidence to suggest that time spent outdoor after school significantly increases the time devoted to moderate and vigorous physical activity participation (Mota et al., 2008). However, in this study the results suggest that time spent in outdoor play has no statistically significant influence on children's daily aerobic step count for the weekdays or weekend days.

This study was the first to investigate study aerobic step count in outdoor play with children. Although statistically significant findings were not found, there were meaningful findings based on the group means differences. Children were engaged in 486 
more aerobic steps each day of the week than the weekend days. The children were asked to report the frequency of outdoor activities they participated in during the week of data collection. These frequencies are reported in Table 9 and provide insight into the aerobic step counts results. Even though the children reported activities of moderate and vigorous intensity such as running, jumping, games, biking, team sports; they also reported that they engaged in activities such as "hanging out", "talking", and "standing" as primary outdoor activities. This suggests that when Costa Rica children spent time outdoors, they are not necessarily engaging in activities that involve moderate or vigorous intensity effort. Further study is needed to better understand how children are spending their time when playing outdoors.

Table 9

Top Five Outdoor Activities that Children Engaged during Data Collection Week

\begin{tabular}{lcc}
\hline \multicolumn{1}{c}{ Outdoor activities } & $n$ & Percentage \\
\hline Free play such as running, jumping, jumping rope, climbing & 135 & $71.10 \%$ \\
trees. & & \\
Playing games such as thieves and police, hide and seek, freeze & 130 & $68.40 \%$ \\
tag, cops and robbers, kickball, swing or slide in. & 128 & $67.40 \%$ \\
Hanging out/talking/standing. & 127 & $66.80 \%$ \\
Biking, skateboarding, or roller-skating. & 122 & $64.20 \%$ \\
Playing/practicing team sports such as soccer, basketball, etc. & & \\
\hline
\end{tabular}

Another meaningful finding, although not statistically different, was that children who spent 1 hour to 2:59 minutes in outdoor play achieved 335 more aerobic steps than 
those engaged in less than 1 hour for the weekdays. This suggests that children may need to stay outdoors for more than one hour to achieve higher aerobic step counts. Spending one hour or more outdoors, it may be a good recommendation for Costa Rican children to implement for the weekdays.

Interestingly, the opposite pattern was found for the weekend days. Children who spent less than one hour outdoors achieved 385 more aerobic steps that those that were engaged in 1 to $2: 59$ minutes in outdoor play. It could be that during the weekend days children have less time to be outdoors, but when they are; they tend to engage in more moderate to vigorous intense activities. Caution needs to be taken when interpreting these findings since no statistical significant results were reported. However, these findings have important implications for health promotion in addressing outdoor play and intensity among children. To better understand the relationship between outdoor play and intensity, more investigation is needed.

In addition, the finding that boys demonstrated a significantly higher daily aerobic step count over the weekdays when is compared to girls has important public health implications for Costa Rica health promotion organizations. Girls take significantly lower daily aerobic step counts than boys all days of the week. Generally, boys tend to participate in more vigorous activity than girls (Trost, Rosenkranz, \& Dzewaltowski, 2008). During free play, lunch, and before school, boys are significantly more active than girls in terms of moderate-to-vigorous physical activity (Blatchford, Baines \& Pellegrini, 2003; Mckenzie, Marshall, Sallis, \& Conway, 2000; Zask, van Beurden, Barnett, Brooks \& Dietrich, 2001). Although not measured, the researchers observed similar differences in behaviors during the recess breaks. While the reasons behind sex differences are not 
widely established, boys tend to spend more time engaged in active play, while girls engage more opportunities to socialize with friends. This tends to reinforce the view that boys are put into social contexts that allow for more opportunities to engage in physically vigorous activities (Blatchford, et al., 2003; Ridgers, Carte, Stratton, \& McKenzie, 2011). Instead girls tend to participate in games that are less vigorous (Blatchford, et al., 2003; Ridgers, et al., 2011). These finding supports the hypothesis that boys acquired a higher daily aerobic (MVPA) step counts than girls over the weekdays.

\section{Summary}

The results of this study have shown that more time spent in outdoor play partially influence children's step count. Encouraging children to spend three or more hours in outdoor play may be a useful strategy for increasing daily step counts over the weekdays that school is in session. Overall, boys engaged in more daily steps and more aerobic steps than girls for all days of the week. In addition, there are only a few children who participated in this study sample that met step count recommendations. Future investigation should focus on identifying the behavioral mechanisms associated with inactivity among Costa Rican children. Finally, both daily average step count and average aerobic step count for the weekend days were lower when compared to weekdays counts. Further research is needed to better understand Costa Rican children's outdoor play and physical activity behavior during the week and on the weekend days.

\section{Conclusions and Future Research Recommendations}

The following conclusions can be drawn from this study:

1. It appears that encouraging children to spend 3 or more hours in outdoor play may be a useful strategy for increasing daily step counts over the weekdays. 
2. Boys engage in more daily steps than girls for all days of the week. Research is needed to identify the physical activity behavioral mechanisms associated with inactivity among Costa Rican girls.

3. Children's step count in Costa Rica differs from the weekdays and the weekend days. Additional research is required to ascertain the reason for this difference.

4. According to the findings in this study, an interesting pattern was found for both daily average step count and average aerobic step count for the weekend days. Further research is needed to better understand children's physical activity behavior and outdoor play patterns over the weekend days.

5. Boys take more daily aerobic (moderate-to-vigorous) steps than girls regardless of day of the week. Further research is necessary to understand how intensity dimension influences outdoor play.

6. Few children who participated in this study sample met the United States step count recommendation. Even though these findings cannot be generalized to all the children in Costa Rica, these findings suggest a need for intervention and further investigation. 


\section{References}

Abbott, R. A., \& Davis, P. S. W. (2004). Habitual physical activity and physical activity intensity: Their relation to body composition in 5.0-10.5-year old children. European Journal of Clinical Nutrition, 58, 285-291.

Ainsworth, B. E., Haskell, W. L., Whitt, M. C., Irwin, M. L., Swartz, A. M., Strath, S. J., O’Brien, W. L., Bassett D. R. Jr., Schmitz, K. H., Emplaincourt, P. O., Jacobs, D. R. Jr., \& Leon, S. A. (2000). Compendium of physical activities: An update of activities and MET intensities. Medicine and Science in Sports and Exercise, $32(9$ Suppl), S498-504.

American College of Sports Medicine. (2009). Preschooler's activity declines between ages 2 and 5. Retrieved September 3, 2010, from http://www.acsm.org/AM/Template.cfm?Section=Home\&TEMPLATE=/CM/Conte ntDisplay.cfm\&CONTENTID=11939

American Heart Association. (2010). Physical activity and Children. Retrieved October 2, 2010 from http://www.heart.org/HEARTORG/GettingHealthy/PhysicalActivity-and-Children_UCM_304053_Article.jsp

Barfield, J. P., Rowe, D. A., \& Michael, T. J. (2004). Interinstrument consistency of the Yamax Digi-Walker pedometer in elementary school-aged children. Measurement in Physical Education and Exercise Science, 8(2), 109-116. 
Beighle, A., Morgan, C. F., Le Masurier, G., \& Pangrazi, R. P. (2006). Children's physical activity during recess and outside of school. Journal of School Health, 76 (10), 516-520.

Beighle, A., \& Pangrazi, R. P. (2006). Measuring children's activity levels: The association between step-counts and activity time. Journal of Physical Activity and Health, 3(2), 221-229.

Bell, A. C., \& Dyment, J. E. (2006). Grounds for action: Promoting physical activity through school ground greening in Canada. Evergreen. Retrieved October 3, 2010 from http://www.evergreen.ca/en/resources/schools/research-policy.sn

Bird, W. (2004). Natural fit: Can green space and biodiversity increase levels of physical activity? Royal Society for the Protection of Birds. Retrieved from http://www.rspb.org.uk/Images/natural_fit_full_version_tcm9-133055.pdf

Blatchford, P., Baines, E., \& Pellegrini, A. (2003). The social context of school playground games: sex and ethnic difference, and changes over time after entry to junior school. British Journal of Developmental Psychology, 21(2), 481-505.

Boreham, C., \& Riddoch, C. (2001). The physical activity, fitness and health of children. Journal of Sports Science, 19(12), 915-929.

Brage, S., Wedderkopp, N., Elekund, U., Franks, P. W., Wareham, N. J., Bo Andersen, L., \& Froberg, K. (2004). Features of the metabolic syndrome associated with objectively measured physical activity and fitness in Danish children. Diabetes Care, 27(9), 2141-2148.

Bronfenbrenner, U. (2005). Making human beings human: Bioecological perspectives on human development. Thousand Oaks, CA: Sage Publications. 
Brusseau, T. A., Kulinna, P. H., Tudor-Locke, C., Ferry, M., van der Mars, H., \& Darst, P. W. (2011). Pedometer-determined segmented physical activity patterns of fourth- and fifth-grade children. Journal of Physical Activity and Health, 8, 279286.

Burdette, H. L., \& Witaker, R. C. (2005). Resurrecting free play in young children: Looking beyond fitness and fatness to attention, affiliation and affect. Archives of Pediatrics \& Adolescent Medicine, 159, 46-50.

Burdette, H., Whitaker, R., \& Daniels, S. (2004). Parental report of outdoor playtime as a measure of physical activity in preschool-aged children. Archives of Pediatrics \& Adolescent Medicine, 158, 353-357.

Caspersen, C. J., Powell, K. E., \& Christenson, G. M. (1985). Physical activity, exercise, and physical fitness: Definitions and distinctions for health-related research.

Public Health Report,100(2), 126-31.

Centers for Disease Control and Prevention [CDC]. (1998). Youth risk behavior surveillance: United States, 1997. Morbidity and Mortality Weekly Report, 47, 189.

Centers for Disease Control and Prevention [CDC] (2005). Barriers to children walking to or from school-United States, 2004. Morbidity and Mortality Weekly Report, 54(38), 949-952. http://www.cdc.gov/mmwr/preview/mmwrhtml/mm5438a2.htm Centers for Disease Control and Prevention [CDC]. (2010). Physical activity for everybody: Glossary of terms. Retrieved from http://www.cdc.gov/physicalactivity/everyone/glossary/ 
Children's Play Council (2002). More than swings and roundabouts: Planning for outdoor play. National Children's Bureau. Retrieved September 6, 2010, http://www.ncb.org.uk/dotpdf/open\%20access\%20\%20phase\%201\%20only/moreswing2_cpc_20050512.pdf

Cleland, W., Crawford, D., Baur, L. A., Hume, C., Timperio, A., \& Salmon, J. (2008). A prospective examination of children's time spent outdoors, objectively measured physical activity and overweight. International Journal of Obesity, 32(11), 16851693.

Clements, R. (2004). An investigation of the status of outdoor play. Contemporary Issues in Early Childhood, 5(1), 68-80.

Clements, R. (Ed.) (2005). Elementary school recess: Selected readings, games, and activities for teachers and parents. Boston: American Press.

Clinical Trials Research Unit, Synovate. (2010). A National Survey of Children and Young People's Physical Activity and Dietary Behaviours in New Zealand: 2008/09 - Key Findings. New Zealand, Wellington: Ministry of Health.

Cohen, J. (1992). A power primer. Psychological Bulletin, 112(1), 155-159.

Cooper, A. R., Bo Andersen, L., Wedderkopp, N., Page, A. S., \& Froberg, K. (2005). Physical activity levels of children who walk, cycle or are driven to school. American Journal of Preventive Medicine, 29(3), 179-184.

Cooper, A. R., Page, A. S., Foster, L. J., \& Qahwaji, D. (2003). Commuting to school: Are children who walk more physically active? American Journal of Preventive Medicine, 25(4), 273-276. 
Corbin, C. B., Pangrazi, R. P., \& Le Masurier, G. C. (2004). Physical activity for children: Current patterns and guidelines. President's Council on Physical Fitness and Sports Research Digest, 5(2), 1-8.

Cordell, H. K., Bets, C. J., \& Green, G. T. (2009). National Kids Survey: A recreation research report in the IRIS Series. Retrieved from http://warnell.forestry.uga.edu/nrrt/nsre/IrisReports.html

Cox, M., Schofield, G., Greasley, N., \& Kolt, G. S. (2005). Pedometer steps in primary school-aged children: A comparison of school-based and out-of-school activity. Journal of Science \& Medicine in Sport, 9(1), 91-97.

Craig, R., Mindell, J., \& Hirani, V. (eds) (2009). Health Survey for England 2008: Physical activity and fitness. Volume 1: Physical activity and fitness. London: NHS Information Centre for Health and Social Care.

de Vries, S., Verheij, R. A., Groenewegen, P. P., \& Spreeuwenberg, P. (2003). Natural environments-healthy environments? An exploratory analysis of the relationship between greenspace and health. Environment and planning, A35, 1717-1731.

Department of Health, Physical Activity, Health Improvement and Prevention. (2004). At least five a week: Evidence on the impact of physical activity and its relationship to health. London: Department of Health.

Dietz, W. (2006). Cited in exchange every day. Retrieved September 6, 2010, from http://www.childcareexchange.com/eed/issue.php?id=1440 
Douglas, I. (2005). Urban greenspace and mental health, review paper prepared for UK MAB Urban Forum. Retrieved September 7, 2010 from http://www.ukmaburbanforum.co.uk/Downloadable\%20Pubs/ ukmabgrnspcepap2.pdf

Ferreira, I., van der Horst, K., Wendel-Vos, W., Kremers, S., van Lenthe, F., \& Brug, J. (2007). Environmental correlates of physical activity in youth - a review and update. Obesity Reviews, 8(2), 129-154.

Fjørtoft, I. (2001). The natural environment as a playground for children: The impact of outdoor play activities in pre-primary school children. Early Childhood Education Journal, 29 (2), 111-117.

Florez, M., Martinez, R., Chacra, W., Stickman-Stein, N., \& Levis. S. (2007). Outdoor exercise reduces the risk of hypovitaminosis D in obese. Journal of Steroid Biochemistry \& Molecular Biology, 103, 679-681.

Fox, K. R. (2004). Childhood obesity and the role of physical activity. Journal of the Royal Society for the Promotion of Health, 124(1), 34-39.

Frost, J. L. (2006). The dissolution of children's outdoor play: Causes and consequences. Presented to The Value of Play: a forum on risk, recreation and children's health, 31st May. Retrieved September, 6, 2010, from http://www.ipema.org/Documents/Common\%20Good\%20PDF.pdf

Giles-Corti, B., Kelty, S. F., Zubrick, S. R., \& Villanueva, K. P. (2009). Encouraging walking for transport and physical activity in children and adolescents: How important is the built environment? Sports Medicine, 39(12), 995-1009. 
Goran, M. I., Reynolds, K. D., \& Lindquist, C. H. (1999). Role of physical activity in the prevention of obesity in children. International Journal of Obesity and Related Metabolic Disorders. 23(suppl 3), S18- S33.

Groves, L., \& McNish, H. (2008). Baseline study of play at Merrylee Primary School, Glasgow. Forestry Commission Scotland. Retrieved September 8, 2010 from http://www.merrylee-pri.glasgow.sch.uk/News/Story.aspx?SectionId=c30b4e8e873e-4dae-80b0-5beab58cd58f\&StoryId=57445ad6-fcbb-42fe-a550$8 \mathrm{a} 06 \mathrm{~b} 753222 \mathrm{c}$

Hands, B., \& Larkin, D. (2006). Physical activity measurement methods for young children: A comparative study. Measurement in Physical Education \& Exercise Science, 10(3), 203-214.

Hands, B., \& Parker, H. (2008). Pedometer-determined physical activity, BMI, and waist girth in 7- to 16-year-old children and adolescents. Journal of Physical Activity \& Health, 5 (supp 1), S153-S165.

Harms, J. M., \& Lettow, L. J. (Summer 2007). Nurturing children's concepts of time and chronology through literature. Childhood Education, 83(4), 211-218.

Hartig, T., Mang, M., \& Evans, G. W. (1991). Restorative effects of natural environment experiences. Environment and Behavior, 23(1), 3-26.

Haug, E., Torsheim, T., Sallis, J. F., \& Samdal, O. (2010). The characteristics of the outdoor school environment associated with physical activity. Health Education Research, 25(2), 248-256.

Hills, A. P., \& Byrne, N. M. (2006). State of the science: A focus on physical activity. Asia Pacific Journal of Clinical Nutrition, 15(Suppl), 40-48. 
Hinkley, T., Crawford, D., Salmon, J., Okely, A. D., \& Hesket, K. (2008). Preschool children and physical activity: A review of correlates. American Journal of Preventive Medicine, 34 (5), 435-441.

Hofferth, S. L., \& Sandberg, J. F. (2001). Changes in American children's use of time, 1981-1997. In: T., Owens \& S. L., Hofferth, (eds). Children at the Millennium: Where Have We Come From, Where Are We Going? (193-229). Amsterdam, the Netherlands: Elsevier Science Publishers.

Holbrook, E. A., Barreira, T. V., \& Kang, M. (2009). Validity and reliability of Omron pedometers prescribed and self-paced walking. American College of Sports Medicine, 41(3) 669-673.

Hoos, M. B., Gerver, W. J. M., Kester, A. D., \& Westerterp, K. R. (2003). Physical activity levels in children and adolescents. International Journal of Obesity, 27, 605-609.

Hussey, J., Bell, C., Bennett, K., O’Dwyer, J., \& Gormley, J. (2007). Relationship between the intensity of physical activity, inactivity, cardiorespiratory fitness and body composition in 7-10-years-old Dublin children. British Journal of Sports Medicine, 41(5), 311-316.

Hussey, J., Bell, C., \& Gormley, J. (2007). The measurement of physical activity in children. Physical Therapy Reviews, 12(1), 52-58.

Inhelder, B., \& Piaget, J. (1962). The growth of logical thinking. New York: Basic Books. International Association for the study of Obesity [IASO] (2010). IASO prevalence data: Children \& Adolescents. Retrieved September 18, 2010 from http://www.iaso.org/policy/trackingobesity/ 
Johnson, T. G., Brusseau, T. A., Graser, S. V., Darst, P. W., \& Kulinna, P. H. (2010). Step counts of 10- to 11-year-old children by ethnicity and metropolitan status. Journal of Physical Activity and Health, 7(3), 355-363.

Kahn, P. H., \& Kellert, S. R. (2002). Children and nature: Psychological, sociocultural and evolutionary investigations. Cambringe, Masschusetts: Massachusetts Institute of Technology Press.

Kang, M., Bassett, D. R., Barreira, T. V., Tudor-Locke, C., Ainsworth, B., Reis, J. P., Strath, S., \& Swartz, A. (2009). How many days are enough? A study of 365 days of pedometer monitoring. Research Quarterly for Exercise and Sport, 80(3), 445453.

Kaplan, R. \& Kaplan, S. (1989). The experience of nature: A psychological perspective. Cambridge, NY: Cambridge University Press.

Karsten, L. (2005). It all used to be better? Different generations on continuity and change in urban children's daily use of space. Children's Geographies, 3(3), 275290.

Kohl III, H., \& Hobbs, K. (1998). Development of physical activity behaviors among children. Pediatrics, 101(3), 549-554.

Kong, L. (2000). Nature's dangers, nature's pleasures: Urban children and the natural world. In S. L. Holloway \& G. Valentine (Eds.), Children's geographies (257271). London: Routledge.

Koplan, J. P., Liverman, C. T., \& Kraak, V. I. (2005). Preventing childhood obesity: Health in the balance. Washington DC: National Academies Press. 
Korpela, K., M., Hartig, T., Kaiser, F. G., \& Fuhrer, U. (2001). Restorative qualities of favorite places. Environmental and Behavior, 33(4), 572-589.

Lang, D. M., Butz, A. M., Duggan, A. K., \& Serwint, J. R. (2007). Physical activity in urban school-aged children with asthma. Pediatrics, 113(4), 341-346.

Le Masurier, G. C., Beighie, A., Corbin, C. B., Darst, P. W., Morgan, M., Pangrazi, R. P., Wilde, B., \& Vincent, S. D. (2005). Pedometer determined physical activity levels of youth. Journal of Physical Activity \& Health, 2, 159-168.

Leather, P., Pyrgas, M., Beale, D., \& Lawrence, C. (1998). Windows in the workplace. Environment and Behavior, 30(6), 739-763.

Little, H., \& Wyver, S. (2008). Outdoor play: Does avoiding the risks reduce the benefits? Australian Journal of Early Childhood, 33(2), 33-40.

Lobstein, T., Baur, L., \& Uauy, R. (2004). Obesity in children and young people: A crisis in public health. Obesity Reviews, 5(Suppl. 1), 4-85.

Louv, R. (2005). Last child in the woods: Saving our children from nature-deficit disorder. Chapel Hill, NC: Algonquin.

Lovell, R., \& Roe, J. (2009). Physical and mental health benefits of participation in Forest School. Countryside Recreation, 17(1), 20-23.

Mackett, R. L. \& Paskins, J. (2008). Children's physical activity: The contribution of playing and walking. Children \& Society, 22(5), 345-357.

McKenzie T. L., Marshall S. J., Sallis, J. F., \& Conway, T. L. (2000). Leisure-time physical activity in school environments: an observational study using SOPLAY. Preventive Medicine, 30(1), 70-77. 
Malecka-Tendera, E., \& Mazur, A. (2006). Childhood obesity: A pandemic of the twenty-first century. International Journal of Obesity, 30, S1-S3.

Mannion, G., Sankey, K., Doyle, L., \& Mattu, L. (2006). Young people’s interaction with natural heritage through outdoor learning. Scottish Natural Heritage Commissioned Report no. 225 (ROAME No. F06AB03).

Martorell, R., Khan, L. K., Hughes, M. L., \& Grummer-Strawn, L. M. (1998). Obesity in Latin American women and children. Journal of Nutrition. 128(9), 1464-1473.

Mason C. (2000). Transport and health: En route to a healthier Australia? The Medical Journal of Australia, 172 (5): 230-232.

Miles, L. (2007). Physical activity and health. Nutrition Bulletin, 32(4), 314-363.

Mitchell, R., \& Popham, F. (2007). Greenspace, urbanity and health: Relationship in England. Journal of Epidemiol Community Health, 61(8), 681-683.

Mota, J., Silva, P., Aires, L., Santos, M. P., Oliveira, J.. \& Ribeiro, J. C. (2008). Differences in school-day patterns of daily physical activity in girls according to level of physical activity. Journal of Physical Activity \& Health, 5, S90-S97.

Muñoz, S. A. (2009). Children in the outdoors: A literature review. Sustainable Development Research Centre. Retrieved from http://www.countrysiderecreation.org.uk/Children\%20Outdoors.pdf National Association for Sport \& Physical Education (NASPE). (2007). Guideline for schoolers. Retrieved September 3, 2010, from http://www.aahperd.org/naspe/standards/nationalGuidelines/PA-Children-512.cfm 
Nielsen, T. S., \& Hansen, K. B. (2007). Do green areas affect health? Results from a Danish survey on the use of green areas and health indicators. Health \& Place, $13(4), 839-850$.

Nilsson, K., Baines, C., \& Konijnendijk, C. C. (eds). (2007). Final Report, COST Strategic Workshop:Health and the Natural Outdoors. Retrieved September 4, 2010, from http://www.sl.life.ku.dk/upload/cost_strategic_workshop_final_report_web.pdf NPFA, Children's Play Council \& PLAYLINK. (2000). Best play: What play provision should do for children. London: NPFA.

Núñez-Rivas, H., Monge-Rojas, R., León, H., \& Roselló, M. (2003). Prevalence of overweight and obesity among Costa Rican elementary school children. Revista Panamericana de la Salud Publica/Pan American Journal of Public Health, 13(1), 25-32.

Oja, P., Bull, F. C., Fogelholm, M., \& Martin, B. W. (2010). Physical activity recommendations for health: What should Europe do? BioMed Central Public Health, 10, 10.

Oliver, M., Schofield, G., \& Kolt, G. (2007). Physical activity in preschoolers: Understanding prevalence and measurement issues. Sports Medicine, 37(12), 1045-1070.

Omron Healthcare. (2007). Omron instruction manual: Pocket Pedometer model HJ720ITC. Bannockburn, Illinois: Omron Healthcare, INC. 
Page, A. S., Cooper, A. R., Griew, P., Davis, L., \& Hillsdon, M. (2009). Independent mobility in relation to weekday and weekends physical activity in children aged 10-11 years: The PEACH project. International Journal of Behavioral Nutrition and Physical Activity, 6, 2.

Pangrazi, R., Beighle, A., Vehige, T., \& Vack, C. (2003). Impact of Promoting Lifestyle Activity for Youth (PLAY) on children's physical activity. Journal of School Health, 73(8), 317-321.

Parley, T., Meriwether, R., Baker, E., Watkins, L., Johnson, C., \& Webber, L. (2007). Safe play spaces to promote physical activity in inner-city children: Results from a pilot study of an environmental intervention. American Journal of Public Health, 97(9), 1625-1631.

Parsons, R., Tassinary, L. G., Ulrich, R. S., Hebl, M. R., \& Grossman-Alexander, M. (1998). The view from the road: Implications for stress recovery and immunization. Journal of Environmental Psychology, 18(2), 113-140.

Pate, R. R., Baranowski, T., Dowda, M., \& Trost, S. G. (1996). Tracking of physical activity in young children. Medicine and Science in Sport and Exercise, 28(1), 9296.

Pate, R. R., Long, B. J., \& Heath, G. (1994). Descriptive epidemiology of physical activity in adolescents. Pediatric Exercise Science, 6, 434-447.

Pate, R. R., Pfeiffer, K. A., Trost, S. G., Ziegler, P., \& Dowda, M. (2004). Physical activity among children attending preschools. Pediatrics, 114(5), 1258-1263.

Piaget, J. (1969). The child's conception of time. New York: Ballantine Books. 
Piaget, J. (1970). The child's conception of movement and speed. New York: Basic Books.

Pretty, J., Peacock, J., Hine, R., Sellens, M., South, N., \& Griffin, M. (2007). Green exercise in the UK countryside: Effects on health and physiological well-being and implications for policy and planning. Journal of Environmental Planning and Management, 50(2), 211-231.

Purslow, L. R., Hill, C., Saxton, J., Corder, K., \& Wardle, J. (2008). Differences in physical activity and sedentary time in relation to weight in 8-9 year old children. International Journal of Behavioral Nutrition and Physical Activity, 5 (67).

Raustorp, A., Pangrazi, R. P., \& Stahle, A. (2004). Physical activity level and body mass index among schoolchildren in southeastern Sweden. Acta Paediatrica, 93(3), 400-404.

Report to Natural England (March, 2009). Childhood and nature: A survey on changing relationships with nature across generations. Retrieved September 3, 2010, from http://www.englandmarketing.co.uk/index.php/news/89-children-outdoors

Rickinson, M., Dillon, J., Teamey, K., Morris, M., Choi, M. Y., Sanders, D., \& Benefield, P. (2004). A review of research on outdoor learning. Retrieved September 8, 2010 from http://www.field-studiescouncil.org/documents/general/NFER/NFER\%20Exec\%20Summary.pdf

Ridgers, N. D., Carter, L. M., Stratton, G., \& McKenzie, T. L. (2011). Examining children's physical activity and play behaviors during school playtime over time. Health Education Research, 26. Doi: 10.1093/her/cyr014 
Rivkin, M. S. (1995). The great outdoors: Restoring children's right to play outside. Washington, DC: National Association for the Education of Young Children.

Rowe, D. A., Mahar, M. T., Raedeke, T. D., \& Lore, J. (2004). Measuring physical activity in children with pedometers: Reliability, reactivity, and replacement of missing data. Pediatric Exercise Science, 16(4), 343-354.

Rowland, T. W. (1990). Exercise and children's health. Champaign, IL: Human Kinetics Publishers, 31-45.

Ruiz, J. R., Rizzo, N. S., Hurtig-Wennlöf, A., Ortega, F. B., Warnberg, J., \& Sjöström, M. (2006). Relations of total physical activity and intensity to fitness and fatness in children: The European youth heart study. American Journal of Clinical Nutrition, 84(2), 299-303.

Sallis, J., \& Owen, N. (2002). Ecological models of health behavior. In: K. Glanz, B.K. Rimer, F.M. Lewis (eds). Health Behavior and Health Education: Theory, Research \& Practice (462-484). San Francisco, CA: Jossey-Bass.

Sallis, J. F., Nadir, P. R., Broyles S. L., Berry, C. C., Elder, J. P., McKenzie, T. L., \& Nelson, J. A. (1995). Correlates of physical activity at home in MexicanAmerican and Anglo-American preschool children. Health Psychology, 12, 390398.

Sallis, J. F., Owen, N., \& Fisher, E. B. (2008). Ecological models of health behavior. In: K., Glanz, B. K., Rimer, \& K., Viswanath, (eds). Health Behavior and Health Education. (465-485). San Francisco, CA: John Wiley \& Sons, Inc. 
Sallis, J. F., Prochaska, J. J., \& Taylor, W. C. (2000). A review of correlates of physical activity and adolescents. Medicine and Science in Sports and Exercise, 32(5), 963-975.

Scruggs, P. W. (2007). Quantifying activity time via pedometer in fifth- and sixth-grade physical education. Journal of Physical Activity and Health, 4(2), 215-227.

Scruggs, P. W., Beveridge, S. K., Eisenman, P. A., Watson, D. L., Shultz, B. B., \& Ransdell, L. B. (2003). Quantifying physical activity via pedometry in elementary physical education. Medicine and Science in Sports and Exercise. 35(6), 10651071.

Senda, K., \& Kuwabara, J. (2007). Involving nursery school children in the design process of play structures. Children, Youth and Environments, 17(1), 326-327.

Sharma, M. (2007). International school-based interventions for preventing obesity in children. Obesity Reviews, 8(2), 155-167.

Sirard, J., \& Pate, R. (2001). Physical activity assessment in children and adolescents. Sports Medicine, 31(6), 439-454.

Spinks, A., Macpherson, A., Bain, C., \& McClure, R. (2006). Determinants of sufficient daily activity in Australian primary school children. Journal of Paediatrics \& Child Health, 42(11), 674-679.

Strauss, R. S., Rodzilsky, D., Burack, G., \& Colin, M. (2001). Psychosocial correlates of physical activity in healthy children. Archives of Pediatrics \& Adolescents Medicine, 155(8), 897-902. 
Strong, W. B., Malina, R. M., Blimkie, C. J. R., Daniles, S. R., Dishman, R, K., Gutin, B., Hegenroeder, A. C., Must, A., Nixon, P. A., Pivarnk, J. M., Rowland, T., Trost, S., \& Trudeau, F. (2005). Evidence based physical activity for school-age youth. Journal of Pediatrics, 146(6), 732-737.

Tabbush, P., \& O'Brien, E. (2003). Health and well-being: Trees, woodlands and natural spaces. Forestry Commission, Edinburgh.

Tandy, C. (1999). Children's diminishing play space: A study of intergenerational changes in children's use of their neighbourhoods. Australian Geographical Studies, 37(2), 154-162.

Taras, H. (2005). Physical activity and student performance at school. Journal of School Health, 75(6), 214-218.

Taylor, A. F., \& Kuo, F. E. (2008). Children with attention deficits concentrate better after walk in the park. Journal of Attention Disorders, 12(5), 402-409.

Thompson, A. M., Rehman, L. A., \& Humbert, M. L. (2005). Factors influencing the physical active leisure of children and youth: A qualitative study. Leisure Sciences: An interdisciplinary Journal, 27(5), 421-438.

Trost, S. G., Pate, R. R., Saunders, R., Ward, D. S., Dowda, M., \& Felton, G. (1997). A prospective study of the determinants of physical activity in rural fifth-grade children. Preventive Medicine, 26(2), 257-263.

Trost, S. G., Rosenkranz, R. R., \& Dzewaltowski, D. (2008). Physical activity levels among children attending after-school programs. Medicine \& Science in Sports \& Exercise, 40(4), 622-629. 
Tudor-Locke, C. (2002). Taking steps towards increased physical activity: Using pedometers to measure and motivate. President's Council on Physical Fitness and Sports Research Digest, 3(17).

Tudor-Locke, C., Johnson, W.D., \& Katzmarzyk, P.T. (2010). Accelerometer-determined steps per day in US children and youth. Medicine \& Science in Sports \& Exercise, 42(12), 2244-2250.

Tudor-Locke, C., Lee, S. M., Morgan, C. F., Beighle, A., \& Pangrazi, R. P. (2006). Children's pedometer-determined physical activity during the segmented school day. Medicine \& Science in Sports \& Exercise, 38(10), 1732-1738.

Tudor-Locke, C., MaClain, J. J., Hart, T. L., Sisson S. B., \& Washington T. L. (2009a). Expected values for pedometer-determined physical activity in youth. Research Quarterly for Exercise and Sport, 80(2), 164-174.

Tudor-Locke, C., MaClain, J. J., Hart, T. L., Sisson S. B., \& Washington T. L. (2009b). Pedometry methods for assessing free-living youth. Research Quarterly for Exercise and Sport, 80(2), 175-184.

Tudor-Locke, C., Pangrazi, R. P., Corbin, C. B., Rutherford, W. J., Vincent, S. D., Raustrop, A., Tomson, L. M., \& Cuddihy, T. F. (2004). BMI-referenced standards for recommended pedometer-determined steps/day in children. Preventive Medicine, 38, 857-864.

U. S. Department of Health and Human Services. (1996). Physical activity and health: A report of the Surgeon General. Atlanta, GA: Centers for Disease Control and Prevention. Retrieved September 08, 2010, from http://www.cdc.gov/nccdphp/sgr/sgr.htm 
U. S. Department of Health \& Human Services (HHS). (2008). Active children and adolescents. In U. S. Department of Health \& Human Services (eds.), 2008 Physical activity guidelines for Americans: Retrieved from ttp://www.health.gov/paguidelines/guidelines/chapter3.aspx

U.S. Department of Health and Human Services, Health Resources and Services Administration, Maternal and Child Health Bureau. (2009). The National Survey of Children's Health 2007. Rockville, Maryland: U.S. Department of Health and Human Services.

Valentine, G., \& McKendrick, J. (1997). Children's outdoor play: Exploring parental concerns about children's safety and the changing nature of childhood. Geoforum, 28(2), 219-235.

van Sluijs, E. M. F., McMinn, A. M., \& Griffin, S. J. (2007). Effectiveness of interventions to promote physical activity in children and adolescents: Systematic review of controlled trials. British Medical Journal, 335, 703-707.

Veitch, J., Bagley, S., Ball, K., \& Salmon, J. (2005). Where do children usually play? A qualitative study of parent's perceptions of influences on children's active freeplay. Health and Place, 12(4), 383-393.

Vincent, S. D., \& Pangrazi, R. P. (2002). An examination of the activity patterns of elementary school children. Pediatric Exercise Science, 14(4), 432-441.

Vincent, S. D., Pangrazi, R. P., Raustorp, A., Michaud Tomson, L., \& Cuddihy, T. F. (2003). Activity levels and body mass index of children in the United States, Sweden, and Australia. Medicine and Science in Sports and Exercise, 35(8), 1367-1373. 
Wadsworth, B. J. (1996). Piaget's theory of cognitive affective development. Reading, MA: Addison-Wesley.

Wang, Y., \& Lobstein, T. (2006). Worldwide trends in childhood overweight and obesity. International Journal of Pediatric Obesity, 1(1), 11-25

Wang, Y., Monteiro, C., \& Popkin, B. M. (2002). Trends of obesity and underweight in older children and adolescents in the United States, Brazil, China, and Russia. American Journal of Clinical Nutrition, 75(6), 971-977.

Warburton, D. E. R., Nicol, C. W., \& Bredin, S. S. D. (2006). Health benefits of physical activity: The evidence. Canadian Medical Association Journal, 174(6), 801-809.

Ward Thompson, C., Aspinall, P., \& Montarzino, A. (2008). The childhood factor: Adult visits to green places and the significance of childhood experience. Environment and Behaviour, 40(1), 111-143.

Wells, N. M. (2000). At home with nature: Effects of "greenness" on children's cognitive functioning. Environment and Behaviour, 32(6), 775-795.

Wells, N. M., \& Lekies, K. S. (2006). Nature and the life course: Pathways from childhood nature experiences to adult environmentalism. Children, Youth and Environments, 16(1), 1-24.

Wen, L. M., Kite, J., Merom, D., \& Rissel, C. (2009). Time spent playing outdoor after schools and its relationship with independent mobility: A cross-sectional survey of children aged 10-12 years in Sydney, Australia. International Journal of Behavioral Nutrition and Physical Activity, 6, 15. 
World Health Organization. (2010). Global recommendations on physical activity for health. Retrieved September 8, 2010 from http://whqlibdoc.who.int/publications/2010/9789241599979_eng.pdf

Zask, A., van Beurden, E., Barnett, L., Brooks, L. O., \& Dietrich, U. C. (2001). Active school playgrounds: Myth or reality? Results of the "Move It Groove It" project. Preventive Medicine, 33(5), 402-408.

Zhou, Z., Peverly, S. T., Boehm, A. E., \& Chongde, L. (2000). American and Chinese children's understanding of distance, time and speed interrelations. Cognitive Development, 15(2), 215-240. 
Appendices 
Appendix A-Descriptive Information Pertaining to each Participating School 
Table 10

Descriptive Information Pertaining to Each Participating School

\begin{tabular}{|c|c|c|c|c|c|}
\hline \multirow[t]{2}{*}{ Schools } & Population & Classification & School & Physical & Social Economic \\
\hline & (Estimated) & based on MEP & Schedul & Education & Status \\
\hline
\end{tabular}

Teacher

School $1 \quad 1000$ students $\quad{\text { Management } 5^{\mathrm{a}}}_{\text {Mixed }^{\mathrm{b}}} \quad$ Yes $\quad$ Low or

below low

School 2950 students $\quad$ Management $5^{\mathrm{a}}$ Mixed $^{\mathrm{b}}$ Yes High, medium and medium-low

School 3850 students $\quad$ Management $5^{\mathrm{a}}$ Mixed $^{\mathrm{b}} \quad$ Yes $\quad$ Medium to Low

Note. ${ }^{\mathrm{a}}$ Management 5 means school with over 850 students; ${ }^{\mathrm{b}}$ double schedule. MEP $=$ Ministerio de Educación Pública, Costa Rica. (Ministry of Public Education, Costa Rica)

In Costa Rica most of the schools in the metropolitan area have mixed double schedules to provide more opportunities for children to get an education. The first schedule is from 7 a.m. until 12:10 p.m., and the second schedule is from 12:30 p.m. until 5:40 p.m.

All school provided recess for their students. The morning recess schedules included three recess periods. The first recess began at 8:20 a.m. (15 min. or $5 \mathrm{~min}$.), the second at 9:50 a.m. (10 min or $20 \mathrm{~min}$.) and the third recess started at 11:25 a.m. (5 min). The afternoon schedules also had three recess periods. The first period began at 1:50 p.m. (15 min or $5 \mathrm{~min}$.), the second period started at 3:20 p.m. (10 min or $20 \mathrm{~min}$.) and the third at 4:55 p.m. (5 min). All principals reported that all fifth grade classes received physical education one day per week for 1 hour and 20 minutes. 
The main social problems faced by these schools are: drug addiction, alcoholism, family disintegration, domestic violence, prostitution and different levels of abuse (i.e., psychological, physical). Two of the schools have an interdisciplinary team (that includes counselor, psychologist, and social worker) to address these social issues that their students face. Table 11 describes the environmental context of each school. 
Table 11

Environmental context Pertaining to Each Participating School

\begin{tabular}{|c|c|c|c|c|c|c|}
\hline \multirow[t]{2}{*}{ School characteristics } & \multicolumn{2}{|c|}{ School 1} & \multicolumn{2}{|c|}{ School 2} & \multicolumn{2}{|c|}{ School 3} \\
\hline & Yes & No & Yes & No & Yes & No \\
\hline It can be accessed by car, public & $\mathrm{X}$ & & $\mathrm{X}$ & & $\mathrm{X}$ & \\
\hline \multicolumn{7}{|l|}{ transportation, walking or cycling } \\
\hline Has fencing around & $\mathrm{X}$ & & $X$ & & $\mathrm{X}$ & \\
\hline Has school cafeteria (free or reduce & $\mathrm{X}$ & & $\mathrm{X}$ & & $\mathrm{X}$ & \\
\hline \multicolumn{7}{|l|}{ lunches) } \\
\hline Has pulperia (small super market to buy & $X$ & & $X$ & & $\mathrm{X}$ & \\
\hline \multicolumn{7}{|l|}{ food and drinks during recess) } \\
\hline Has computer lab & $\mathrm{X}$ & & $\mathrm{X}$ & & $\mathrm{X}$ & \\
\hline Has library & $\mathrm{X}$ & & $\mathrm{X}$ & & $\mathrm{X}$ & \\
\hline Has green spaces for children to play & $\mathrm{X}$ & & & $\mathrm{X}$ & & $\mathrm{X}$ \\
\hline Has sport plaza or concrete slab for & $\mathrm{X}$ & & $\mathrm{X}$ & & $\mathrm{X}$ & \\
\hline \multicolumn{7}{|l|}{ children to play and physical education } \\
\hline \multicolumn{7}{|l|}{ classes } \\
\hline Has playground & & $\mathrm{X}$ & & $\mathrm{X}$ & & $\mathrm{X}$ \\
\hline Offers special accomodations for special & $\mathrm{X}$ & & $\mathrm{X}$ & & $\mathrm{X}$ & \\
\hline needs students & & & & & & \\
\hline
\end{tabular}


Appendix B—Children's Outdoor Play Survey 
February, 2011

Dear Student:

As a doctoral student in the College of Education at Auburn University and a faculty member on leave from the Sport Science School at National University, I am currently working on my dissertation focusing on the children's outdoor play and its relationship to physical activity levels, fitness and weight status. As a student in the fifth grade, you have been selected to participate in this study. Your responses will help us understand how important outdoor play is for fifth graders.

Enclosed you will find a questionnaire with questions relating to personal information as well as questions regarding your outdoor play, outdoor activities and the amount of freedom you have to play outside by yourself). This survey should take about 20 minutes to complete.

Please be assured that all responses will be kept confidential and will only be read by the researcher. Your participation in this study will in no way affect your standing in school. Thanks you for your cooperation.

Sincerely,
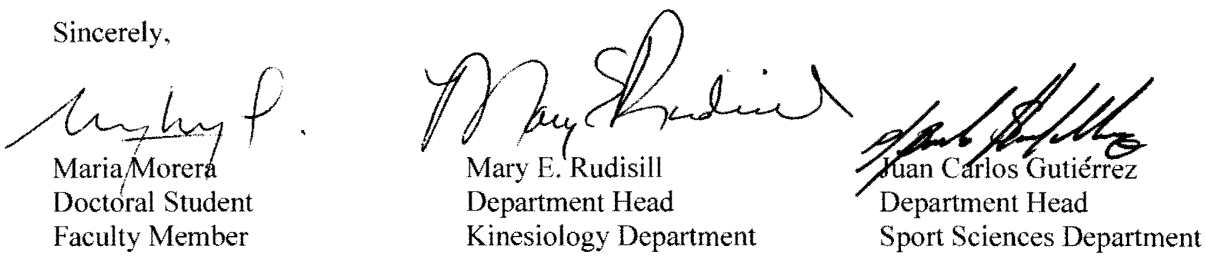


\section{Children's Outdoor Play Survey}

\section{General Instructions}

We are interested in learning about children's outdoor play. The questions will ask you about the time you spend outdoors, types of outdoor activities you like to do, and your outdoor independence. Please answer each question as accurately as possible as it relates to your situation. There is no right or wrong answer. Please think about how much time you spend outdoors during the weekdays (Monday through Friday) and the weekend (Saturday and Sunday).

All the information you provide will only be read by the researcher and will remain confidential. Please fill in the space or check the box (whichever is applicable) that best represents your answer. Thank you for your cooperation.

Sincerely,

Maria Morera

mrmc2479@gmail.com

Researcher

\section{Part I. This section is about you}

1. Your name is

2. Your birthday (day, month, year) is

3. Are you a...
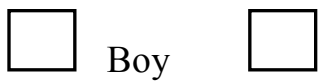

Girl

4. In which country were you born?

5. Using numbers, how many brothers and sisters do you have? Older Brothers I don't have brother or sisters Older Sisters

Younger Brothers

Younger Sisters

\section{Part II. The following questions are related to your outdoor play.}

In the following questions write over the blank space or mark with an $\mathrm{X}$ over the option that best describes your situation 
6. Think about your last week. Now please answer

How much time did you spend playing outdoors over the weekday (Monday through Friday), per day?

\begin{tabular}{|c|c|c|c|c|c|c|}
\hline None & $\begin{array}{c}1 \text { to } 30 \\
\text { minutes }\end{array}$ & $\begin{array}{l}31 \text { to } 59 \\
\text { minutes }\end{array}$ & $\begin{array}{l}1 \text { to } 2 \\
\text { hours }\end{array}$ & $\begin{array}{l}2 \text { to } 3 \\
\text { hours }\end{array}$ & $\begin{array}{l}3 \text { to } 4 \\
\text { hours }\end{array}$ & $\begin{array}{l}4 \text { or more } \\
\text { hours }\end{array}$ \\
\hline
\end{tabular}

7. Think about your last week. Now please answer

How much time did you spend playing outdoors on the weekend (Saturday and Sunday), per day?

\begin{tabular}{|c|c|c|c|c|c|c|}
\hline None & $\begin{array}{c}1 \text { to } 30 \\
\text { minutes }\end{array}$ & $\begin{array}{l}31 \text { to } 59 \\
\text { minutes }\end{array}$ & $\begin{array}{c}1 \text { to } 2 \\
\text { hours }\end{array}$ & $\begin{array}{l}2 \text { to } 3 \\
\text { hours }\end{array}$ & $\begin{array}{c}3 \text { to } 4 \\
\text { hours }\end{array}$ & $\begin{array}{c}4 \text { or more } \\
\text { hours }\end{array}$ \\
\hline
\end{tabular}

8. Think about your last week. Now please answer.

How much time did you spend playing outdoors in vigorous-intensity activities on a weekday (yesterday)? Examples of vigorous-intensity activities (you feel out of breath and sweaty) include: active games involving running and chasing, jumping rope, martial arts, sports such cycling, aerobics, soccer, basketball, tennis, running, swimming etc.

\begin{tabular}{|c|c|c|c|c|c|}
\hline None & 1 to 9 min & $\begin{array}{c}10 \text { to } 19 \\
\min \end{array}$ & 20 to $29 \min$ & $\begin{array}{c}30 \text { to } 59 \\
\text { min }\end{array}$ & 60 min and over \\
\hline
\end{tabular}

9. Think about your last week. Now please answer.

How much time did you spend playing outdoors in moderate-intensity activities on a weekday (yesterday)? Examples of moderate-intensity activities (child feels warm and slightly out of breath) include: hiking, skateboarding, bicycle riding, brisk walking, weight lifting, doubles tennis, volleyball, etc

\begin{tabular}{|c|c|c|c|c|c|}
\hline None & 1 to $9 \mathrm{~min}$ & $\begin{array}{c}10 \text { to } 19 \\
\mathrm{~min}\end{array}$ & 20 to $29 \mathrm{~min}$ & $\begin{array}{c}30 \text { to } 59 \\
\mathrm{~min}\end{array}$ & $60 \mathrm{~min}$ and over \\
\hline
\end{tabular}


10. Think about your last week. Now please answer.

How much total time did you spend playing outdoors in light-intensity activities on a weekday (yesterday)? Examples of light intensity activities include: standing, walking slowly, lifting lightweight objects, sitting outdoor playing with the pet, etc.

\begin{tabular}{|c|c|c|c|c|c|}
\hline None & 1 to 9 min & $\begin{array}{c}10 \text { to } 19 \\
\text { min }\end{array}$ & 20 to $29 \mathrm{~min}$ & $\begin{array}{c}30 \text { to } 59 \\
\text { min }\end{array}$ & 60 min and over \\
\hline
\end{tabular}

11. Think about your last week. Now please answer

How much total time did you spend playing outdoors in vigorous-intensity activities on a weekend day? Examples of vigorous-intensity activities (child feels out of breath and sweaty) include: active games involving running and chasing, jumping rope, martial arts, sports such cycling, aerobics, soccer, basketball, tennis, running, etc.

\begin{tabular}{|c|c|c|c|c|c|}
\hline None & 1 to 9 min & $\begin{array}{c}10 \text { to } 19 \\
\min \end{array}$ & 20 to $29 \mathrm{~min}$ & $\begin{array}{c}30 \text { to } 59 \\
\min \end{array}$ & 60 min and over \\
\hline
\end{tabular}

12. Think about your last week. Now please answer

How much time did you spend playing outdoors in moderate-intensity activities on a weekend day? Examples of moderate-intensity activities (child feels warm and slightly out of breath) include: hiking, skateboarding, bicycle riding, brisk walking, weight lifting, double tennis, volleyball, etc

\begin{tabular}{|c|c|c|c|c|c|}
\hline None & 1 to 9 min & $\begin{array}{c}10 \text { to } 19 \\
\min \end{array}$ & 20 to $29 \mathrm{~min}$ & $\begin{array}{c}30 \text { to } 59 \\
\min \end{array}$ & 60 min and over \\
\hline
\end{tabular}

13. Think about your last week. Now please answer

How much total time did you spend playing outdoors in light-intensity activities on a weekend day? Examples of light intensity activities include: standing, walking slowly, lifting lightweight objects, sitting outdoor playing with the pet, etc.

\begin{tabular}{|c|c|c|c|c|c|}
\hline None & 1 to $9 \mathrm{~min}$ & $\begin{array}{c}10 \text { to } 19 \\
\mathrm{~min}\end{array}$ & 20 to $29 \mathrm{~min}$ & $\begin{array}{c}30 \text { to } 59 \\
\mathrm{~min}\end{array}$ & $60 \mathrm{~min}$ and over \\
\hline
\end{tabular}


14. Think about your last week. Now please answer

Did your parents play with you outdoors?

\begin{tabular}{|l|l|}
\hline Yes & No \\
\hline
\end{tabular}

15. Think about your last week. Now please answer

How frequently did your parents play with you outdoors?

\begin{tabular}{|c|c|c|c|c|}
\hline Never & Seldom & Some what & Often & Always \\
\hline
\end{tabular}

16. Think about your last week. Now please answer

In which of these outdoor activities did you participate?

\begin{tabular}{|l|l|}
\hline $\mathbf{X}$ & \multicolumn{1}{|c|}{ Outdoor activities } \\
\hline & Hanging out/talking/standing. \\
\hline & Listening to music, watching movies or using electronic devices. \\
\hline & Reading or studying while sitting outdoors. \\
\hline & Sitting playing with a pet. \\
\hline & Free play such as running, jumping, jumping rope, climbing trees, etc. \\
\hline & Playing/practicing team sports such as soccer, basketball, volleyball, etc. \\
\hline & $\begin{array}{l}\text { Playing/practicing individual sports such as tennis, biking, track and field, } \\
\text { martial arts, triathlon. }\end{array}$ \\
\hline & $\begin{array}{l}\text { Playing/practicing adventure activities such as mountain biking, kayaking, } \\
\text { canoeing, surfing, climbing, etc. }\end{array}$ \\
\hline & $\begin{array}{l}\text { Playing games such as thieves and police, hide and seek, freeze tag, cops and } \\
\text { robbers, kickball, swing or slide in. }\end{array}$ \\
\hline & Playing/exploring nature, forest, gardens, etc. \\
\hline & Walking/running playing with the pet. \\
\hline & Biking, skateboarding, or roller-skating. \\
\hline & Riding motorcycles, jet skiing, etc. \\
\hline & Swimming, diving, snorkeling in rivers, pools or the sea. \\
\hline & Attending camps, field trips, hiking, fishing, outdoor classes, etc. \\
\hline & Attending in cultural and/or musical activities outdoors. \\
\hline & Riding horses. \\
\hline & Bird watching, wildlife viewing, nature study. \\
\hline & Working in gardens, seed plants, picking fruits and vegetables, etc. \\
\hline & $\begin{array}{l}\text { Volunteer work at National Parks, Biological Reserves, cleaning rivers, seed } \\
\text { trees. }\end{array}$ \\
\hline & Farming, feeding or taking care of animals (grooming, brushing, etc). \\
\hline & Watering plants, flowers, and gardens. \\
\hline & Washing car/motorcycle/bike, windows, etc. \\
\hline
\end{tabular}


17. Think about your last week. Now please answer

How much time did you spend playing outdoors over the weekday (Monday through Friday), per day?

\begin{tabular}{|c|c|c|c|c|c|c|}
\hline None & $\begin{array}{c}1 \text { to } 30 \\
\text { minutes }\end{array}$ & $\begin{array}{l}31 \text { to } 59 \\
\text { minutes }\end{array}$ & $\begin{array}{l}1 \text { to } 2 \\
\text { hours }\end{array}$ & $\begin{array}{l}2 \text { to } 3 \\
\text { hours }\end{array}$ & $\begin{array}{l}3 \text { to } 4 \\
\text { hours }\end{array}$ & $\begin{array}{c}4 \text { hour or } \\
\text { more }\end{array}$ \\
\hline
\end{tabular}

18. Think about your last week. Now please answer

How much time did you spend playing outdoors on the weekend (Saturday and Sunday), per day?

\begin{tabular}{|c|c|c|c|c|c|c|}
\hline None & $\begin{array}{c}1 \text { to } 30 \\
\text { minutes }\end{array}$ & $\begin{array}{l}31 \text { to } 59 \\
\text { minutes }\end{array}$ & $\begin{array}{c}1 \text { to } 2 \\
\text { hours }\end{array}$ & $\begin{array}{l}2 \text { to } 3 \\
\text { hours }\end{array}$ & $\begin{array}{l}3 \text { to } 4 \\
\text { hours }\end{array}$ & $\begin{array}{c}4 \text { hour or } \\
\text { more }\end{array}$ \\
\hline
\end{tabular}

19. Read the following statements, and mark an " $X$ " on the option that indicates the level of frequency with which you perform them

\begin{tabular}{|l|l|l|l|l|l|}
\hline \multicolumn{1}{|c|}{ Statements } & Never & Seldom & $\begin{array}{l}\text { Some } \\
\text { times }\end{array}$ & Often & Always \\
\hline I walk by myself near our place of residence. & & & & & \\
\hline I walk to school by myself. & & & & & \\
\hline I walk to school with my friends. & & & & & \\
\hline I walk to my friend's houses. & & & & & \\
\hline I play in the front yard by myself. & & & & & \\
\hline I play in the front yard with my friends. & & & & & \\
\hline I play around the block by myself. & & & & & \\
\hline I play around the block with my friends. & & & & & \\
\hline $\begin{array}{l}\text { I play by myself in the field (plaza) or park near } \\
\text { my home. }\end{array}$ & & & & & \\
\hline I play by myself in the neighborhood playground. & & & & & \\
\hline I play with my friends in the field (plaza) or park \\
near my home.
\end{tabular}




\begin{tabular}{|l|l|l|l|l|l|}
\hline \multicolumn{1}{|c|}{ Statements } & Never & Seldom & $\begin{array}{l}\text { Some } \\
\text { times }\end{array}$ & Often & Always \\
\hline $\begin{array}{l}\text { I play in the field (plaza) or park near my home } \\
\text { under adult supervision. }\end{array}$ & & & & & \\
\hline $\begin{array}{l}\text { I play in the neighborhood playground under } \\
\text { adult supervision. }\end{array}$ & & & & & \\
\hline I am allowed to go everywhere on my own. & & & & & \\
\hline
\end{tabular}

Thank you so much for your participation in this study. If you have additional comments please feel free to use the space below to do so. If you have any questions, please contact me (Maria Morera) at mzm0015@tigermail.auburn.edu or mrmc24792@gmail.com. 


\section{Child Additional Information Form}

(Completed by researchers only)

Child name:

School:

Date of birth:

\section{Weight Status}

Height:

Weight:

\section{Physical Activity}

Pedometer \#:

Stride length:

Issue date:

Return date: 
Appendix C-Letter to Parent/Guardian's Consent 


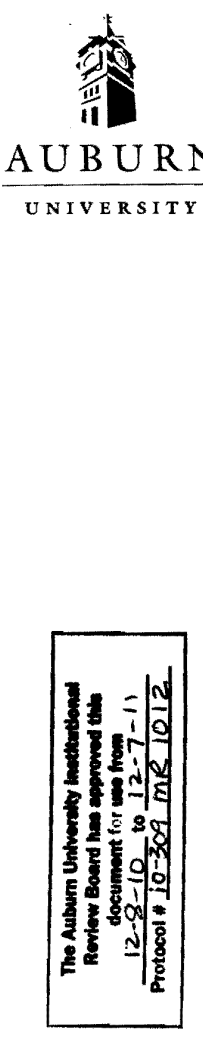

2050 BEARD-EAVES

Memorial Coliseun

AuBurn, AL 36849.5323

TelePHONE:

$334-844-4483$

Fax:

$334-844-1467$

www.auburn.edu
COLLEG OF EDUCATION

DEPARTMENT OF KINESIOLOG

\section{INFORMED CONSENT FOR EXPLORING CHILDREN'S OUTDOOR PLAY AND ITS RELATIONSHIP WITH PHYSICAL ACTIVITY, FITNESS AND WEIGHT STATUS}

I invite your child to participate in a research project that will be completed within the Ministry of Education at your child's Elementary School. We are interested in exploring your child's outdoor play and how this factor may influence their physical activity, fitness level, and weight status. The assessment measures will include descriptive information along with physical activity (measured by step count pedometers), fitness (measured by Progressive Aerobic Cardiovascular Endurance Run [PACER]), and children's outdoor play survey.

Step count pedometers will be used to assess their physical activity participation for seven days (five week days and one weekend). It takes approximately 5 minutes or less to place the step counts pedometers on your child.

Descriptive information including height, weight, and waist circumference will be measured for your child. Height will be measured using a standard tape measure. Children will be asked to stand with their back against a wall and height will be measured to the nearest centimeter. Children will also stand on a standard scale to measure their weight to the nearest kilogram. Body Mass Index, a measure of overweight and obesity, will be calculated from the height and weight measures using the formula height divided by weight. Waist circumferences will be measured using a standard tape measure. The tape will be placed around the waistband of the child's school uniform to measure waist circumference.

Physical activity assessments include step count pedometers and the PACER.

1. Pedometers will be used to assess children's physical activity for seven days. Pedometers will be attached to the waistband of each child uniform by an investigator. These devices are small and lightweight $(28 \times 27 \times 10 \mathrm{~mm} \times 17 \mathrm{~g})$. The step count pedometer counts the number of steps while the child is awake. Your child will receive a demonstration and explanation on how to wear the pedometer, and how and when to remove it (only during showering, bathing, swimming or sleeping).

2. PACER will be used to assess children's fitness levels (aerobic capacity). This test is a multistage test that involves running back and forth across a 20 -meter course in time with prompts played from a CD. A sound will indicate when an individual should reach the end of each lap. The number of laps achieved by the child will be recorded. The test will end when the child does not make the lap on time on two occasions. This test is often used in Physical Education to assess fitness levels.

Page 1 of 2 Parental/Guardian initials 


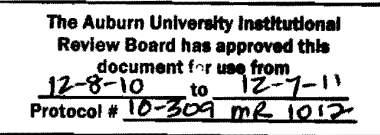

Children's outdoor play survey includes a series of questions related to your child's outdoor play. The questions are associated with (1) time spent outdoors, (2) adult supervised and independent play, and (3) types and intensity of outdoor activities. Children will be asked to answer the survey during a regular school day in the presence of their regular classroom teacher. Parents/guardians will be asked to answer the same questions using the Children's Outdoor Play Parents Survey. Descriptive information will be included in the surveys. Children will be asked to report their sex, place of birth, date of birth and number of siblings. Parents/guardians will be asked to report child's sex, place of birth, date of birth, number of siblings, and family's social economic status

There are no foreseeable risks or discomforts associated with the step count pedometers. The only identified risk for using pedometers is that a child may feel that the monitor is uncomfortable or distracting. These monitors have been used in scientific studies and applied settings (e.g., physical education) with school-aged children for many years. Since the PACER test involves a basic locomotor skill (i.e., running), there is a possibility that your child could experience a minor injury, if he/she falls. Although it is unlikely that you child will experience an injury during the PACER test, we will implement the recommended test protocol for the PACER to minimize this potential physical risk. This will include: proper spacing between children during the test, adequate adult supervision, and requiring shoes during the test. We will encourage all participants to be careful and to respect each other's personal space. In case your child does experience an injury, basic protocol used at your child's school will be followed. Your child's regular teacher will administer first aid, if needed. Your child's teacher will inform you of the injury, if one occurs. If the injury is serious, the school will call 911 , and inform you immediately of the situation. Please note that any child who expresses a desire to quit the assessments will be allowed to stop immediately. To preserve confidentiality, the children's performance and responses will be reported as group results only. Unless otherwise notified by you, I plan to present the results of this program assessment at scientific conferences and publish the results in appropriate journals. In any presentation or publication, the data will remain anonymous.

Your decision whether or not to allow your child to participate will not jeopardize his/her future relations with Auburn University, the Department of Kinesiology and National University, Sports Science School. Your child's performance or responses will in no way affect your child's standing in school. Should you have any questions or desire further information, please call MSc. Maria Morera at 2261-0032 or mzm0015@tigermail.auburn.edu ormrmc2479@gmail.com (emails).

For more information regarding your rights as a research participant you may contact the Auburn University Office of Human Subjects Research or the Institutional Review Board by USA phone (334)-844-5966 or e-mail at hsubjec@auburn.edu or IRBChair@auburn.edu. 
HAVING READ THE INFORMATION PROVIDED YOU MUST DECIDE WHETHER OR NOT TO ALLOW YOUR CHILD TO PARTICIPATE. YOUR SIGNATURE

INDICATES YOUR WILLINGNESS TO ALLOW YOUR CHILD'S PARTICIPATION IN THE STUDY.

Child's Name

Parent/Guardian Signature Date

ID Costa Rican number

Investigator Signature

Date

Page 3 of 3

The Auburn University Institution

Reviow Board has approved this

12/ do 8 io 10 in use from

$\frac{12 / 8}{\text { Protocol }=10-309}$ to $\frac{12}{m e}$ lol

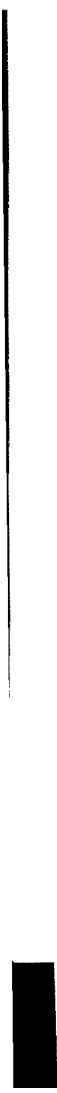


Appendix D-Minor Assent Form 


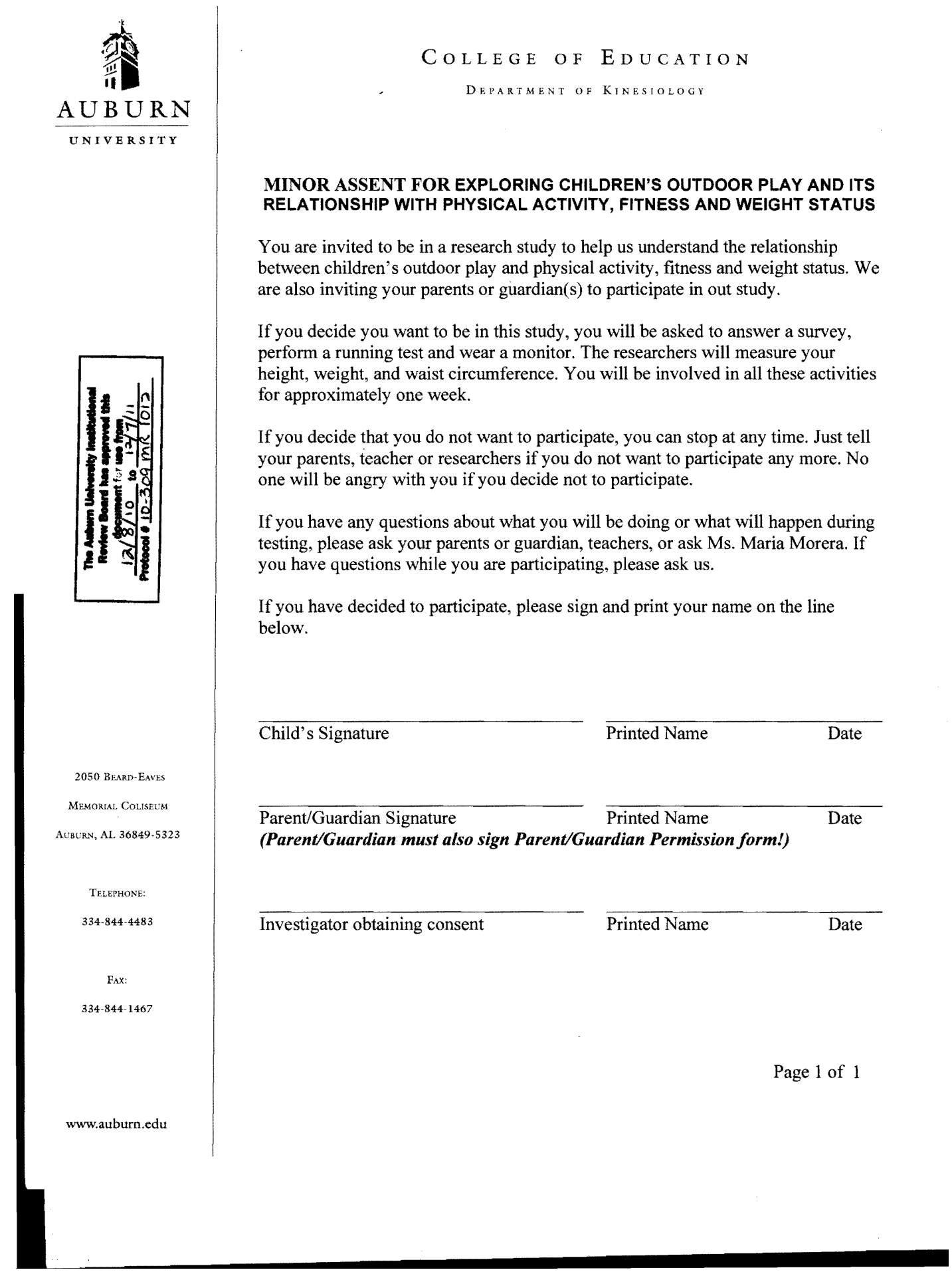


Appendix E-Outdoor Activities Reported by Children Who Met the Step Count Recommendations 
A summary of the outdoor activities reported by those boys and girls who met the step count recommendation are presenting in Tables 12 and 13.

Table 12

Top Weekday Outdoor Activities Reported by the Boys and Girls Who Met the Step Count Recommendations

\begin{tabular}{|c|c|c|c|}
\hline Sex & Outdoor activity & Frequency & Percentage \\
\hline \multirow[t]{8}{*}{ Boys } & Biking, skateboarding, or roller-skating. & 18 & $85.71 \%$ \\
\hline & Playing/practicing team sports such as soccer, & 16 & $76.19 \%$ \\
\hline & basketball, volleyball, etc. & & \\
\hline & Free play such as running, jumping, jumping & 15 & $71.43 \%$ \\
\hline & rope, climbing trees, etc & & \\
\hline & Playing games such as thieves and police, hide & 15 & $71.43 \%$ \\
\hline & and seek, freeze tag, cops and robbers, kickball, & & \\
\hline & swing or slide in & & \\
\hline \multirow[t]{7}{*}{ Girls } & Hanging out/talking/standing. & 23 & $82.14 \%$ \\
\hline & Playing games such as thieves and police, hide & 22 & $78.57 \%$ \\
\hline & and seek, freeze tag, cops and robbers, kickball, & & \\
\hline & swing or slide in. & & \\
\hline & Playing/practicing team sports such as soccer, & 21 & $75 \%$ \\
\hline & basketball, volleyball, etc. & & \\
\hline & Biking, skateboarding, or roller-skating. & 20 & $71.43 \%$ \\
\hline
\end{tabular}

Note. A total of 21 boys and 28 girls meet the step count recommendations. 
Table 13

Top Weekend Day Outdoor Activities Reported by the Boys and Girls Who Met the Step Count Recommendations

\begin{tabular}{|c|c|c|}
\hline Sex & Outdoor activity & \\
\hline
\end{tabular}

\begin{tabular}{|c|c|c|c|}
\hline Boys & Free play such as running, jumping, jumping & 18 & $85.71 \%$ \\
\hline & rope, climbing trees, etc. & & \\
\hline & Walking/running playing with the pet. & 15 & $71.43 \%$ \\
\hline & Playing games such as thieves and police, hide & 14 & $66.67 \%$ \\
\hline & and seek, freeze tag, cops and robbers, kickbal & & \\
\hline & swing or slide in. & & \\
\hline & Biking, skateboarding, or roller-skating. & 14 & $66.67 \%$ \\
\hline Girls & Playing games such as thieves and police, hide & 17 & $94.44 \%$ \\
\hline & and seek, freeze tag, cops and robbers, kickbal & & \\
\hline & swing or slide in. & & \\
\hline & Hanging out/talking/standing. & 14 & $77.77 \%$ \\
\hline & Biking, skateboarding, or roller-skating. & 12 & $66.67 \%$ \\
\hline & Free play such as running, jumping, jumping & 12 & $66.67 \%$ \\
\hline & rope, climbing trees, etc. & & \\
\hline & Sitting playing with a pet. & 12 & $66.67 \%$ \\
\hline & Playing/practicing team sports such as soccer, & 12 & $66.67 \%$ \\
\hline & basketball vollevball etc & & \\
\hline
\end{tabular}

Note. A total of 21 boys and 18 girls meet the step count recommendation. 